This document is confidential and is proprietary to the American Chemical Society and its authors. Do not copy or disclose without written permission. If you have received this item in error, notify the sender and delete all copies.

\title{
Preferred growth orientation of apatite crystals on biological hydroxyapatite enriched with bioactive glass: a biomimetic behavior
}

\begin{tabular}{|r|l|}
\hline Journal: & Crystal Growth \& Design \\
\hline Manuscript ID & cg-2019-00268v.R1 \\
\hline Manuscript Type: & Article \\
\hline Date Submitted by the & $\mathrm{n} / \mathrm{a}$ \\
\hline Complete List of Authors: & $\begin{array}{l}\text { Rincón López, July Andrea; CINVESTAV Queretaro, Materials } \\
\text { Hermann, Jennifer; Centro de Investigación y de Estudios Avanzados } \\
\text { Unidad Querétaro, Materials Science } \\
\text { Cinca-Luis, Núria; Universitat de Barcelona, Centro de Proyección } \\
\text { Térmica (CPT). Dpt. Ciència dels Materials i Química Física } \\
\text { Garrido-Domiguez, Beatriz; Universitat de Barcelona, Centro de } \\
\text { Proyección Térmica (CPT). Dpt. Ciència dels Materials i Química Física } \\
\text { García-Cano, Irene ; Universitat de Barcelona, Centro de Proyección } \\
\text { Térmica (CPT). Dpt. Ciència dels Materials i Química Física } \\
\text { Guilemany-Casadamon , Jose ; Universitat de Barcelona, Centro de } \\
\text { Proyección Térmica (CPT). Dpt. Ciència dels Materials i Química Física } \\
\text { Alvarado-Orozco , Juan ; Centro de Ingeniería y Desarrollo Industrial } \\
\text { Muñoz-Saldaña, Juan; Centro de Investigación y de Estudios Avanzados } \\
\text { Unidad Querétaro, Materials Science }\end{array}$ \\
\hline
\end{tabular}

\section{SCHOLARONE ${ }^{m}$ Manuscripts}




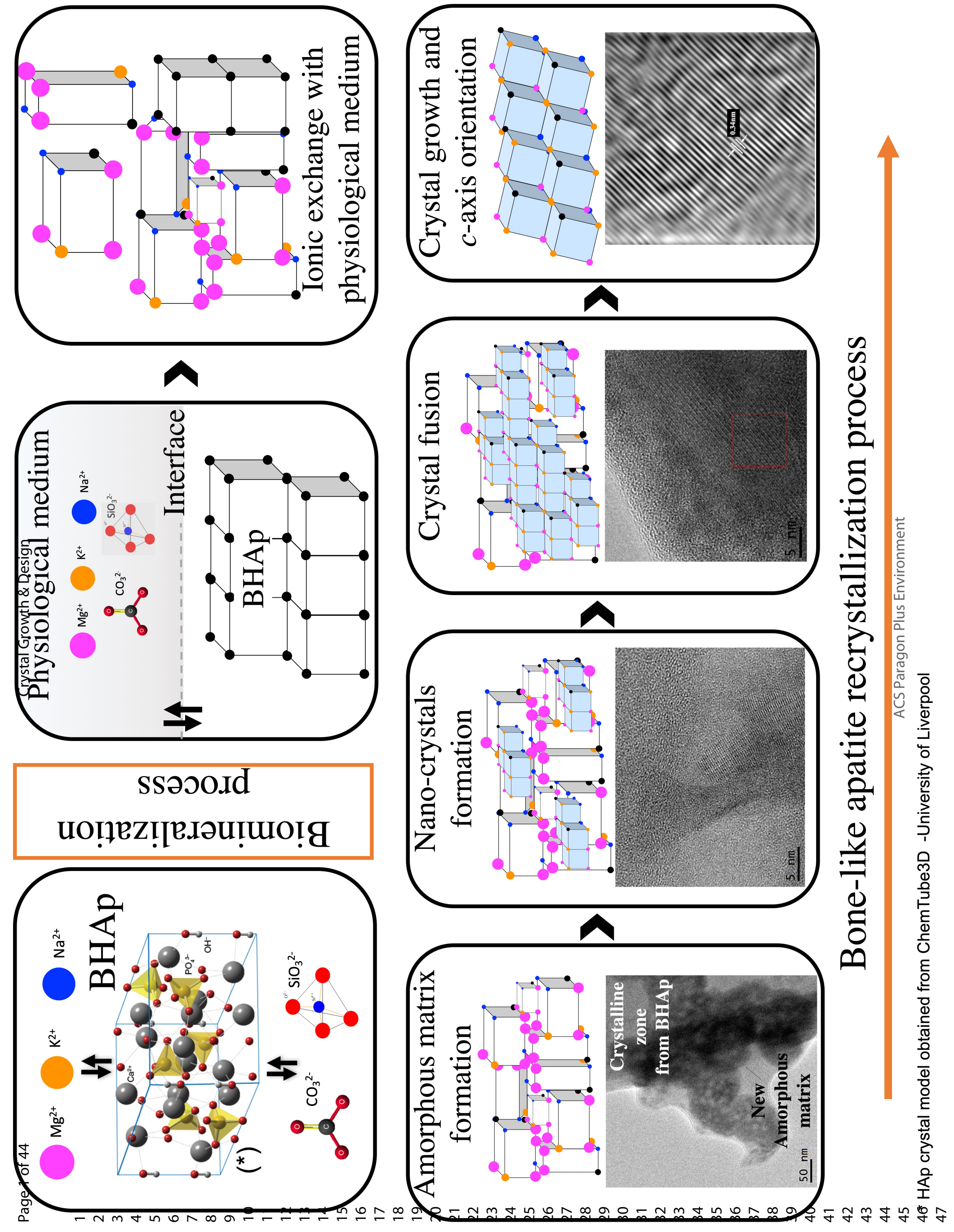




\title{
Preferred growth orientation of apatite crystals on biological hydroxyapatite enriched with bioactive glass: a biomimetic behavior
}

\author{
July Andrea Rincón-López ${ }^{1}$, Jennifer Andrea Hermann-Muñoz ${ }^{1}$, Núria Cinca-Luis ${ }^{2}$, \\ Beatriz Garrido-Domiguez ${ }^{2}$, Irene García-Cano ${ }^{2}$, Jose Maria Guilemany-Casadamon ${ }^{2}$, \\ Juan Manuel Alvarado-Orozco ${ }^{3,4 *}$, Juan Muñoz-Saldaña ${ }^{1 *}$ \\ ${ }^{1}$ Centro de Investigación y de Estudios Avanzados del IPN, Unidad Querétaro, Libramiento Norponiente \\ \#2000, Querétaro, Qro., C.P. 76230, México. \\ ${ }^{2}$ Centro de Proyección Térmica (CPT). Dpt. Ciència dels Materials i Química Física, Universitat de \\ Barcelona, c/Martí i Franquès 1, E-08028 Barcelona, Spain. \\ ${ }^{3}$ Centro de Ingeniería y Desarrollo Industrial, Av. Playa Pie de la Cuesta No. 702, Desarrollo San Pablo, \\ Querétaro, Qro., C.P. 76125, México. \\ ${ }^{4}$ Consorcio de Manufactura Aditiva, CONMAD, Av. Pie de la Cuesta 702, Desarrollo San Pablo, \\ Querétaro, México. \\ *Corresponding authors: jmunoz@cinvestav.mx, juan.alvarado@cidesi.edu.mx
}

\begin{abstract}
The morphological, structural and chemical transformations during the biomineralization process associated with the apatite formation from bovine-derived hydroxyapatite (BHAp) and BHAp/Nagelschmidtite composite obtained from the mixture of BHAp and Vitryxx ${ }^{\circledR}$ bioactive glass are here presented. The study is focused on the structural characteristics of apatite formation and maturation process taking place at the biomaterial surface. The use of a biological HAp is of interest aiming to mimic the natural process of bone mineral matrix formation in the crystallization mechanism. This process was characterized by transmission electron microscopy (TEM), where the initial stage was identified as the formation of a hydrated amorphous matrix followed by the appearance of randomly oriented nanocrystals that later coalesce and grow with preferred orientation to $c$-axis. This behavior is a biomimetic process based on the alignment of natural bone apatite along collagen fibrils. The understanding of natural processes of mineral matrix formation at micro and nanoscale levels on bioactive materials is of great interest to address the effect of size, structure, and composition of apatite nanocrystals on the biologic phenomena involved in osseointegration.
\end{abstract}

Keywords: Biological hydroxyapatite, Nagelschmidtite, apatite crystallization process, preferred orientation, transmission electron microscopy. 


\section{Introduction}

Bioactive ceramics have the capability of bone bonding through the formation of bone-like apatite on its surface leading to an enhancement of bone tissue formation ${ }^{1,2}$. This fact is tightly related to surface reactivity, which determines the biological performance of implanted materials ${ }^{2,3}$. After implantation, several reactions take place at the biomaterialtissue interface generating chemical, morphological and structural changes in the material and the surrounding tissue ${ }^{2}$. The use of bioactive ceramics within the Ca-P-Si family such as Hydroxyapatite (HAp), Silicocarnotite (SC), Nagelschmidtite (Nagel) and bioactive glasses (BG) for bone graft and tissue engineering purposes have attracted considerable attention in the last decades ${ }^{2,4-9}$. A variety of materials and methods have been reported for the synthesis and processing of these bioactive ceramics, including the use of synthetic and biological sources, doping or adding ions to improve their biological responses and mechanical properties, among others ${ }^{6,7,10-13}$. In the case of HAp, several studies have been carried out to increase its osteoconductive and osteoinductive properties and to mimic the behavior of natural apatites by the addition of $\mathrm{CO}_{3}{ }^{2-}, \mathrm{SiO}_{4}{ }^{4-}, \mathrm{Mg}^{2+}, \mathrm{Zn}^{2+}, \mathrm{F}^{-}, \mathrm{Cl}^{-}, \mathrm{Sr}^{2+}$ or $\mathrm{Na}^{+}$ ions ${ }^{13-16}$. In some reports, HAp has been mixed with other bioactive materials such as BG to obtain either ceramic composites or bioactive phases ${ }^{8}$ able to release Si-containing ionic products which may stimulate the osteoblastic cells proliferation, differentiation, as well as the collagen I formation 17,18. Among biological hydroxyapatites, bovine derivedhydroxyapatite (BHAp) is a promising bioactive material due to its natural ionic substitutions. For instance, $\mathrm{Na}^{+}$ions increase the kinetic formation of apatite, facilitating the carbonation process and enhancing the osteoconductivity.

Moreover, $\mathrm{Mg}^{2+}$ ions stimulate the cellular adhesion to biomaterial surfaces and new bone formation 19,20. Previous results have shown that HAp doped with $\mathrm{Mg}^{2+}$ and $\mathrm{Mg}^{2+}$ together with $\mathrm{CO}_{3}{ }^{2-}$ improved the behavior of MSC and MG-63 cells regarding adhesion, proliferation and metabolic activation compared to the stoichiometric one ${ }^{13}$. On the other hand, the economic and environmental implications of HAp extracted from biological source have increased its use for bone graft, as well as for coatings of metallic implants, among other biomedical applications ${ }^{21-23}$.

The bioactivity of glass ceramics and ceramics such as HAp has been widely studied ${ }^{24-28}$. Many efforts have been focused on relating apatite-forming ability of biomaterials evaluated in solutions that simulate body fluid to their in vivo bioactivity and biocompatibility ${ }^{29,30}$. The 
general mechanism for bone-like apatite formation considers a cation exchange of the bioactive material with protons from the body fluid, followed by the formation of an amorphous calcium layer that crystallizes on a Ca-deficient apatite with compositional and structural characteristics of bone mineral ${ }^{31,32}$.

The growth kinetics of the bone-like apatite layer is assumed to be affected by the presence of specific ions (e.g., $\mathrm{CO}_{3}{ }^{2-}, \mathrm{SiO}_{4}{ }^{4-}, \mathrm{Mg}^{2+}, \mathrm{F}^{-}, \mathrm{Cl}^{-}, \mathrm{Na}^{+}$). For instance, the presence of $\mathrm{SiO}_{4}{ }^{4-}$, $\mathrm{SiO}_{2}$, silica-based glasses and Si-doped HAp accelerates the process of biomineralization through the formation of Si-OH groups on its surface, which induces crystalline apatite formation from either an amorphous calcium silicate or an amorphous calcium phosphate (ACP) ${ }^{33}$. On the other hand, it has been reported that the presence of $\mathrm{P}_{2} \mathrm{O}_{5}$ in sol-gel prepared glass can promote the crystal growth of the apatite ${ }^{34}$.

Since the process of bone-like apatite formation involves several microstructural changes, conventional characterization techniques for the bioactivity evaluation include scanning electron microscopy (SEM), X-ray diffraction (XRD) and Raman or infrared spectroscopies 24,29. However, the identification of the first stages of crystallization by XRD is challenging, mainly due to the weak peak intensities generated by small precipitates volume. Further on, the diffraction peaks of the substrates difficult the identification of apatite micro-crystals formed on the bioactive surface ${ }^{35}$.

Multiple studies related to bioactivity and chemical interactions occurring when a bioactive material is immersed in simulated body fluid are available in the literature 24,25,29-31,33,36. However, structural transformations and apatite layer crystallization taking place during the biomineralization process have been scarcely reported. Current efforts to better understand the apatite formation include diverse transmission electron microscopy (TEM) techniques, such as High-Resolution TEM (HR-TEM), selected area electron diffraction (SAED) patterns, Fourier Fast Transform (FFT), Inverse FFT (IFFT), cryoTEM, among others ${ }^{33,36-}$ 41. In contrast to conventional XRD analysis, a TEM techniques offer the potential to investigate the apatite formation mechanisms at the micro- and nano-scale levels to further identify the maturation process, which starts with individual nanocrystals, crystal fusion and finalizes with preferred orientation crystal growth $35,38,42,43$.

This work reports on the morphological, structural and chemical transformations during the biomineralization process of BHAp and BHAp/Nagel composite obtained from the mixture of BHAp and Vitryxx ${ }^{\circledR}$ bioactive glass. Here, not only the use of a biological HAp respective 
to the stoichiometric one and the effect of the bioactive glass enrichment is of interest, but also a particular emphasis is given on the use of TEM techniques to elucidate the mechanism of the bone-like apatite formation as well as further understanding of its growth kinetics.

\section{Material and methods}

\subsection{Sample preparation}

BHAp (Cinvestav, México) ${ }^{7}$ and Bioactive glass (Vitryxx ${ }^{\circledR}$, Germany) ${ }^{44}$ powders were used to prepare dense ceramics following the preparation and characterization methodology reported in a previous group contribution ${ }^{8}$. In a short description, the compositions studied in this work were BHAp and $96.25 \% \mathrm{BHAp}+3.75 \% \mathrm{BG}$ (vol. \%), corresponding to the first two points from the systematic study performed on HAp/BG mixtures from 0 to $30 \mathrm{vol}$. \%, in steps of 3.75\%, by mixtures design using Minitab ${ }^{\circledR}$. The $96.25 \%$ BHAp $+3.75 \%$ BG sample leads exclusive to the formation of BHAp/Nagel composite $(32.7 \mathrm{wt} \% \text { Nagel })^{8}$. For the preparation of ceramics, the powders were milled, followed by a pressing step to form ceramics in disk-shaped green samples previous to a sintering process at $1220{ }^{\circ} \mathrm{C}$ during $4 \mathrm{~h}$ in lab air.

\subsection{Bioactivity and degradation assessment}

The in-vitro biomineralization process on the ceramic samples was studied using the simulated body fluid H8264 (Sigma-Aldrich, Germany), i.e., balanced salt Hank's solution modified with sodium bicarbonate, without phenol red, sterile filtered and suitable for cell culture. The ceramic composite's ability to form apatite after immersion in Hank's solution was evaluated following the ISO/FDIS 23317: 2007(E) standard for ceramics and powders samples ${ }^{45}$. Sintered ceramics were immersed in $25 \mathrm{~mL}$ of Hank's solution and exposed for $0,6,14$ and 28 days at $37^{\circ} \mathrm{C}$. The solution was changed every 3 days to avoid ionic saturation of the medium and sample surface. Before and after immersion, sintered ceramics were characterized using XRD, Raman spectroscopy and SEM/EDX to track the structural, chemical and morphological changes on ceramics and powders surface related to the bonelike apatite formation. TEM/EDX characterization was carried out on sintered BHAp and BHAp/Nagel composite powders to analyze different stages of local transformation of crystalline phases into apatite.

The degradation test was performed based on ISO 10993 standard, Part 14: "Identification 
and quantification of degradation products of ceramic materials" ${ }^{46}$, in which the $\mathrm{pH}$ found on in vivo conditions is simulated. The material was exposed in granulated form to a buffer solution of TRIS (hydroxymethyl aminomethane) with $\mathrm{HCl}, \mathrm{pH}$ of 7.4 at $37^{\circ} \mathrm{C} \pm 1{ }^{\circ} \mathrm{C}$ for $120 \pm 1 \mathrm{~h}$. After the exposure time, the precipitated particles were filtered and dried at $37^{\circ} \mathrm{C}$ during $24 \mathrm{~h}$. The ionic concentrations of the resulting solution were measured using an Inductively Coupled Plasma Optical Emission Spectrometer (ICP-OES, Optima 8300, Perkin Elmer) to determine the leaching products of the samples are within acceptable limits reported in the literature and its effect on the apatite formation.

\subsection{Sample characterization}

\subsubsection{SEM}

Microstructural characterization of sintered ceramics was performed before and after Hank's solution exposure using a Scanning Electron Microscope JSM-7610F (JEOL) at $1 \mathrm{kV}$ electron acceleration voltage and a secondary electron (SE) detector. Samples were sputtercoated with a gold-palladium thin layer to make the ceramic surface conductive. Moreover, the chemical composition of sintered ceramics was measured using an EDX analyzer (Bruker) coupled to the SEM. Grain size was then quantified following the ASTM E112 standard (i.e., linear intercept method) from four micrographs recorded at different magnifications $(500-2500 \mathrm{X})$. The cross-section analysis was performed on fresh fractured ceramics, a $10 \mathrm{kV}$ electron acceleration voltage and a backscattering electron detector were used to evaluate the thickness of the apatite layer.

\subsubsection{GXRD Characterization}

Structural characterization was performed on dense ceramics surface by grazing angle X-ray diffraction (GXRD) with monochromatic CuK $\alpha$ radiation $(\lambda=1.5406 \AA)$ operating at $30 \mathrm{kV}$ and $20 \mathrm{~mA}$ using a Siemens D-500 diffractometer. The XRD patterns were recorded from 10 to $70^{\circ}$ on a $2 \theta$ scale in steps of $0.02^{\circ}$ intervals with a counting time of $2 \mathrm{~s}$ at each step. Structural changes, after different immersion periods (0, 6, 14 and 28 days) in Hank's solution, were measured at a grazing incidence angle of $1^{\circ}$ on the ceramics surface. Rietveld analysis of the XRD patterns was performed using GSAS ${ }^{\circledR}$ to characterize and quantify the phase fraction in each sample, as well as to determine the crystallographic parameters of the 
growing bone-like apatite according to the process and analysis reported elsewhere 7,8 . The $\mathrm{Ca} / \mathrm{P}$ ratio was obtained using the results of Rietveld refinement based on average multiplicity and occupancy values $(O)$ of the $\mathrm{Ca}$, $\mathrm{Ca} 2$ and $P$ atoms in the unit cell of HAp according to equation 1.

$$
C a /_{P}=\frac{(4 \times O C a 1)+(6 \times 0 C a 2)}{(6 \times O P)}
$$

\subsubsection{TEM}

A HR-TEM study was carried out to evaluate the crystalline structure at the nanoscale level and complement the XRD structural analysis to identify the initial and final stages of apatite formation on BHAp and the BHAp/Nagel composite sintered ceramics. For TEM analysis, the ceramic samples were ground in an agate mortar to obtain fine powders and then immersed in Hank's solution for 0, 6 and 28 days. After exposure, the powders were dried in a muffle at $37^{\circ} \mathrm{C}$ during $24 \mathrm{~h}$. In all cases, the powder particles were dispersed in ethanol and deposited on a $\mathrm{Cu}$ holder. The prepared samples were measured in a transmission electron microscope (JEOL 2010F, Japan), equipped with a field emission electron gun and operated at $200 \mathrm{kV}$. Chemical analysis was carried out in a JEOL 2100 LaB6 Transmission Electron Microscope at $200 \mathrm{kV}$ in STEM mode. Energy Dispersive Analysis of X-rays (EDX) was performed using an Oxford Instruments INCA X-sight with $\mathrm{Si}(\mathrm{Li})$ detector and the INCA Microanalysis suite (v.409).

\subsubsection{Raman Spectroscopy}

Raman spectra were recorded at room temperature before and after bioactivity tests in triplicate using a confocal Raman microscope (Bruker SENTERRA) with an excitation source of $532 \mathrm{~nm}$. The measurements were carried out in the $300-3700 \mathrm{~cm}^{-1}$ frequency range, at a spectral resolution of $0.5 \mathrm{~cm}^{-1}$ and an integration time of $40 \mathrm{~s}$. 


\section{Results and discussion}

\subsection{Morphological characterization (SEM)}

The formation of an apatite layer on ceramic's surface was consistently monitored by SEM. Typical micrographs of BHAp and BHAp/Nagel composite before and after bioactivity tests are presented in figures 1 and 2.

Well-defined grain boundaries are observed in the as-sintered BHAp microstructure with a homogeneous grain size distribution of $1.58 \pm 0.21 \mu \mathrm{m}$ and a surface porosity obtained by image analysis of $0.31 \pm 0.16 \%$ (figures $1 \mathrm{a}$, e). In contrast, the as-sintered BHAp/Nagel composite sample showed porosities around $3.03 \pm 0.83 \%$. Two different kinds of microstructural features were identified, one coarse-grained microstructure with the presence of Si-rich precipitates with contents around 4.982 wt.\% and Na-rich areas with contents around $6.450 \mathrm{wt} . \%$ (zone 1) was related to the formation of a secondary phase identified by $\mathrm{XRD}$ as Nagel, which was previously synthesized as a single phase with a composition of $\mathrm{Na}=6.259$ wt. $\%$ and $\mathrm{Si}=4.899$ wt.\%. On the other hand, an homogeneous fine-grained microstructure (zone 2) corresponding to HAp was detected (See figure 2a, e), as reported in a previous work ${ }^{8}$. In BHAp ceramics, after 6 days of exposure, dramatic changes in surface morphology were observed (figures $1 \mathrm{~b}, \mathrm{f}$ ) as a result of an apatite layer formation. Two types of microstructures were detected at this exposure time, a layer with dune-like morphology and below this, a cracked surface with worm-like microstructure. The dune-like layer covered the entire ceramics surface after 14 days (figure 1c) showing a continuous growth of the spherical agglomerates, which after 28 days reached sizes around $4.5 \mu \mathrm{m}$ (figure $1 \mathrm{~d}$ ). A closer look at the agglomerates after 14 and 28 days is shown in figures $1 \mathrm{~g}$ and $\mathrm{h}$, respectively. These agglomerates are formed by submicrometric plate-like crystals, which are growing as a function of immersion time, indicating the crystallization of the bone-like apatite layer ${ }^{18}$.

For the BHAp/Nagel composite, a similar formation mechanism but with higher crystallization kinetic was observed in comparison with BHAp (see figure 2). Unlike the surface morphology of pure BHAp after 6 days, the correspondent of the BHAp/Nagel composite sample was already covered with a well-adhered apatite layer with spherical particles formed with small worm-like aggregates (figure 2b, f). After 14 and 28 days of immersion, the plate-like crystals, as well as the spherical agglomerates are more abundant than in BHAp samples. 
The accelerated formation kinetics in BHAp/Nagel composite ceramics is mainly related to the presence of $\mathrm{Si}$ in the $\mathrm{BG}$, which promotes apatite precipitation due to the defects formation in the HAp lattice (i.e., vacancies or substitutions) and therefore the generation of a more electronegative surface ${ }^{47}$, thus leading to an increase in surface solubility ${ }^{48}$.

The EDX analysis showed an increase in Mg from $0.649 \pm 0.049$ wt. $\%$ to $1.407 \pm 0.125$ wt. $\%$ and $\mathrm{Na}$ from $1.136 \pm 0.138$ wt. $\%$ to $2.945 \pm 0.230$ wt. \%. In contrast, a decrease in $\mathrm{Ca}$ content from $37.057 \pm 0.962$ wt. \% to $28.781 \pm 0.685$ wt. \% with layer growth on pure BHAp samples was observed. No significant changes in $\mathrm{P}$ content were detected. $\mathrm{Mg}$ content showed similar behavior in BHAp/Nagel composite samples, increasing from $0.268 \pm 0.030$ wt. $\%$ to $2.317 \pm 1.202$ wt. $\%$, whereas $\mathrm{Na}$ decreases from $6.021 \pm 0.403$ wt. \% to $3.028 \pm 0.648$ wt. $\%$ and a drop in P content from $22.245 \pm 3.084$ wt. \% to $12.865 \pm 0.986$ wt. \% was observed as the layer was grown. No significant variations in Ca content were identified for the apatite grown on BHAp/Nagel composite samples.

The thickness of the apatite layer was evaluated in micrographs from ceramics cross-sections after 14 (figures 3a, c) and 28 days (figures 3b, d) of exposure. A dense and well-adhered layer was observed for both BHAp and BHAp/Nagel composite ceramics after 14 days.

The apatite final thickness is similar between BHAp $(2.5 \mu \mathrm{m})$ and BHAp/Nagel composite $(2.7 \mu \mathrm{m})$ ceramics. However, for the BHAp/Nagel composite, after 28 immersion days the layer clearly shows better adherence to the surface. The reason for that can be associated to microstructures of Figure $3 \mathrm{~d}$ compared to $3 \mathrm{~b}$ from pure BHAp. In the BHAp/Nagel composite sample the process of apatite formation occurred not only at the surface but also inside the ceramic pores, possibly due to the presence of Nagel phase and the ionic presents in BG. Thus, the pores act as binding sites to the growing apatite on BHAp/Nagel composite samples. This effect can also be observed at the surface of the samples as a function of soaking time (Figure 2). Similar mechanisms have been reported for bioactive silicate ceramics with higher Si contents ${ }^{4}$.

\subsection{Structural characterization}

\subsubsection{GXRD}

The XRD measurements and Rietveld refinements were all consistently done from 10 to 70 $2 \theta\left({ }^{\circ}\right)$. However, the XRD patterns for both samples were plotted in the range between 20- 
$52\left(^{\circ}\right)$ to spotlight the structural changes after Hank's solution immersion as shown in figure 4.The HAp $\left(\mathrm{Ca}_{10}\left(\mathrm{PO}_{4}\right)_{6}(\mathrm{OH})_{2}\right)$ was identified as the main phase in samples with BHAp (figure $4 \mathrm{a}$ ) and $96.25 \% \mathrm{BHAp}+3.75 \% \mathrm{BG}$ (figure $4 \mathrm{~b}$ ), according to the JCPDS 9-432 card: $\mathrm{Pb}_{3} / m$ space group and lattice parameters $a=b=9.432 \AA, c=6.881 \AA$. Moreover, for the $3.75 \%$ BG sample, the Nagelschmidtite $\left(\mathrm{Ca}_{7-\mathrm{x}} \mathrm{Na}_{\mathrm{x}}\left(\mathrm{PO}_{4}\right)_{2+\mathrm{x}}\left(\mathrm{SiO}_{4}\right)_{2-\mathrm{x}} ; \mathrm{x} \leq 2\right)$ was identified as a secondary phase, based on the presence of two diffraction peaks at 31.36 and $33.66^{\circ}$, that correspond to $(026)$ and (220) planes, respectively ${ }^{8}$.

For the Nagel phase, the crystallographic information was taken from ${ }^{49}: P 6_{1}$ space group and lattice parameters $a=b=10.6336(1) \AA, c=21.6422(3) \AA$. As a result, a BHAp/BG mixture in a $0.968 / 0.032$ weight ratio heat-treated at $1220{ }^{\circ} \mathrm{C}$ led to a partial phase transformation of BHAp to 32.74 wt. \% of Nagel phase according to Eq. 1.

$$
0.968 \text { BHAp }+0.032 B G \rightarrow x-y(B H A p)+y \text { (Nagel) }
$$

The Rietveld refinement allowed to calculate strains from $a$ and $c$ lattice parameters, crystallite size and $\mathrm{Ca} / \mathrm{P}$ ratio before and after sample immersion for both compositions. These parameters varied due to the ionic exchange between the material surface and the medium, such as carbonates inclusion in the HAp lattice (Table 1) ${ }^{50,51}$.

A contraction of HAp lattice parameter $a$ was observed in both cases, in comparison with the stoichiometric HAp due to substitutions in the atomic positions of $\mathrm{Ca}^{2+}$ for $\mathrm{Na}^{+}$, also reported by ${ }^{52}$, that favors the carbonated apatite formation due to the $\mathrm{Na}^{+}$substitution, which destabilizes the charge of HAp structure, facilitating the substitution of $\mathrm{PO}_{4}^{3-}$ by $\mathrm{CO}_{3}{ }^{2-}$ to balance the total charge ${ }^{52,53}$ (see Table 1).

From these results, one can see that there are atomic substitutions that led to variations in lattice parameters before immersion, which are not only related to BG additions but also the HAp source (BHAp) ${ }^{7}$. For BHAp and the BHAp/Nagel composite sample, the Ca/P ratios are lower than the stoichiometric value (1.67) showing Ca-deficient HAp in both cases, as expected for biological HAp ${ }^{7,50}$. These changes have a direct effect on the properties of HAp including an increase in solubility and biodegradability in physiological fluid ${ }^{54}$.

GXRD patterns of sintered ceramics exposed in Hank's solution showed an amorphization process described by a broadening of the main peaks that increases with immersion time. These peaks between 30.5 to $34.5^{\circ}$ correspond to (002), (211), (030) planes and exhibited 
specific variations (in-sets in figures 4a-b). For instance, the doublet observed in the (211) plane decreases in intensity tending to form a single peak after 28 days.

On the other hand, the intensity of (002) plane increases as a function of immersion time, which is characteristic of a texturization of the formed apatite associated with a crystal growth along the $c$-axis from HAp structure. This behavior is related to the amorphization and recrystallization processes that is the origin of apatite as a growing new crystalline phase. The formed apatite has a similar structure to HAp but contains atomic substitutions such as $\mathrm{Mg}^{2+}, \mathrm{Zn}^{2+}, \mathrm{F}^{-}, \mathrm{CO}_{3}{ }^{2-}, \mathrm{Cl}^{-}$or $\mathrm{Na}^{+55-57}$.

The crystallite sizes decrease from 271.8 to $40.3 \mathrm{~nm}$ and from 347.7 to $41.7 \mathrm{~nm}$ for BHAp and BHAp/Nagel composite ceramics, respectively. In both cases, crystallite sizes of the formed apatites are very similar to that found in the mineral part of a mammalian bone, where the $c$-axes of plate-shaped apatite crystals are well aligned with the long axes of the collagen fibrils ${ }^{3,58,59}$. On the other hand, after the immersion test the $\mathrm{Ca} / \mathrm{P}$ ratio increase to 1.770 and 1.736 for BHAp and BHAp/Nagel composite samples, respectively. This behavior was previously reported in ${ }^{60,61}$, where the increase of carbonate content absorption led to an increase of the apatite $\mathrm{Ca} / \mathrm{P}$ ratio ${ }^{61}$.

\subsubsection{TEM}

Specific structural changes taking place in samples with compositions BHAp and BHAp/Nagel composite during the immersion tests at 0,6 and 28 days characterized by TEM are described in this section.

As-sintered

Figures 5 and 6 show the HR-TEM micrographs with the IFFT and FFT analysis as well as the SAED patterns of the samples before the immersion. Figures 5a and 6a reveal a highly periodic arrangement of atoms; in both cases, lattice fringes correspond to a lattice spacing of $d=0.854 \mathrm{~nm}$ as shown in insets figures $5 \mathrm{aI}$ and $6 \mathrm{aI}$. The lattice fringes are close to the theoretical value, $d_{(100)}=0.8155 \mathrm{~nm}$ according to JCPDS 9-432 card, where the slight difference can be related to the ionic substitutions in BHAp from natural sources ${ }^{7}$. The SAED pattern for BHAp was indexed considering the [001] zone axis of the HAp unit cell (figure $5 b)$. This region is clearly arranged in a hexagonal shape and matches with the results from the FFT images presented in the insets of figures 5a-II and 6a-II. The same hexagonal 
structure was observed in several areas of the examined BHAp and BHAp/Nagel composite samples. Additionally, the high crystallinity of BHAp and BHAp/Nagel composite samples are in agreement with the narrow and intense peaks of the GXRD pattern (see Fig 4).

Debye rings were observed in the SAED pattern of a different region in BHAp/Nagel composite sample (figure $6 \mathrm{~b}$ ) indicating the presence of a nanocrystalline phase. The analysis of the interplanar distances resulted in the identification of Nagel phase with a lattice spacing $d=0.247 \mathrm{~nm}$, which is comparable with the highest intensity peak of the theoretical (hkl) list that corresponds to $d_{(220)}=0.265 \mathrm{~nm}^{49}$. This related, Rietveld refinement results for the BHAp/Nagel composite sample showed a Nagel content around 32.74 wt.\%, despite the low intensity of the XRD peaks observed for this phase ${ }^{8}$.

After 6 days of immersion

After 6 days, a highly crystalline zone and a matrix in an amorphous state were distinguished for both BHAp and BHAp/Nagel composite samples, presented in figures 7a and 8a, respectively. From these micrographs, one can see that the crystalline BHAp substrate is delimited by a dark zone from the newly formed apatite phase.

The corresponding FFT analysis of the crystalline zones from the BHAp and BHAp/Nagel composite samples are shown in figures 7b-I and 8a-I, respectively. Amorphous zones were determined by the absence of electron-diffraction patterns and are associated with an early stage of the apatite formation. Crystalline zones correspond to the initial HAp phase of both samples. For the BHAp/Nagel composite sample, apatite nanocrystals, which are randomly embedded in the amorphous matrix were observed after 6 days (figure $8 \mathrm{~b}$ ). The apatite nanocrystals lattice fringes were measured and labeled in the IFFT of figure $8 \mathrm{c}$ leading to a $d=0.269 \mathrm{~nm}$ spacing, which corresponds to the (030) plane based on the HAp structure, with a theoretical value of $d=0.271 \mathrm{~nm}$. In contrast, no crystals were observed within the amorphous matrix in the BHAp sample after 6 days as shown in figure 7c.

After 28 days of immersion

After 28 days, elongated crystals with lengths between 20 and $100 \mathrm{~nm}$ were observed for BHAp (figure 9a). These crystals (zone 1) grow from dark areas (zone 2) which have been associated with the formation of ACP clusters ${ }^{37,38,62}$. It has been reported that the geometry of the growing crystals increase their length with $\mathrm{CO}_{3}{ }^{2-}$ content ${ }^{63}$. These growing crystals are overlapped (see figure 9b) in which a single one has approx. $23 \mathrm{~nm}$ length and $10 \mathrm{~nm}$ 
width. On the other hand, in Figure 9c the zone labeled as "new amorphous apatite" presented absence of electron-diffraction patterns and the zone labeled as "crystalline zone from mature apatite" presented a clear SAED of HAp structure (figure 9cI) with an interface between both zones. The amorphous area was always located in the outer zone of the crystal. Crystalline zones were observed along the crystals until the dark zone, which can be related to the apatite recrystallization process and it's inside out formation. Moreover, in figures 10a and 10b, oriented apatite crystals embedded in an amorphous matrix were identified and measured, which is consistent with the observations shown in the FFT (10a-II) and its corresponding IFFT (10a-III). The measured lattice spacing of these crystals was around $0.34 \mathrm{~nm}$, that corresponds to the (002) plane of HAp with a theoretical value of $0.344 \mathrm{~nm}$.

Moreover, formed apatite crystals showed different morphologies for BHAp/Nagel composite sample. The morphology of these crystals shown in figures $11 \mathrm{a}$ and $11 \mathrm{~b}$ has the appearance of interconnected fibers joined by nanosized clusters, similar to ACP (indicated by white arrows $)^{37,38,62}$, all grouped in a continuous and dense matrix with a well-defined boundary. This fiber-like morphology has been previously observed for apatite formed on Bioglass ${ }^{\circledR}$ and was described as needle-like micro-crystal weaving together flake-like crystals $26,28,64$. These areas are composed mostly of $\mathrm{Si}$ and $\mathrm{Mg}$ as identified by EDX. In our case, the presence of $\mathrm{Si}$ is associated to $\mathrm{SiO}_{4}{ }^{4-}$ due to $\mathrm{BG}$ additions, which affects the apatite growth kinetics due to the formation of $\mathrm{SiOH}$ bonds and its polycondensation, favoring the adsorption of $\mathrm{Ca}+\mathrm{PO}_{4}+\mathrm{CO}_{3}{ }^{65}$ and increasing the maturation rate of the crystals.

On the other hand, a significant density of parallel needle arrays was observed in figures $11 \mathrm{c}$ and $11 \mathrm{~d}$, where the $1.56 \mathrm{Ca} / \mathrm{P}$ ratio evidenced the formation of calcium-deficient apatite, typically identified in bioactive calcium phosphates ${ }^{62}$. At this stage, these needle-like crystals have entirely merged with no space between the crystals, which are similar to those observed in BHAp after 28 days. It is worth to mention that the composition and morphology of the observed crystals by TEM are in agreement with the growth of plate-like crystals on dense ceramics surfaces observed by SEM after 14 days of immersion (see inset in figure $2 \mathrm{~g}$ ). Moreover, the compositional gradient detected in the EDX analysis of the cross-sectional view also confirmed the TEM results showing a calcium-deficient apatite with higher $\mathrm{Mg}$ contents.

Thus, all these features suggest a coupled mechanism of apatite formation between the Sicontaining and calcium phosphate phases. 
Additionally, similar SAED patterns identified by FFT were exhibited in the newly formed apatite zone (figure 12a-I) and the mature crystallized apatite zone (figure 12a-II). In both cases, the SAED pattern confirmed at the surface the phase transformation of BHAp to apatite. The lattice fringes associated to a $d=0.238 \mathrm{~nm}$ determined in figure $12 \mathrm{a}-\mathrm{I}$ are similar to those of figure $8 \mathrm{c}$ (early stages of apatite formation), confirming that the apatite crystallization process starts with distances lower than $0.30 \mathrm{~nm}$ and finishes around $0.34 \mathrm{~nm}$, in which the crystals grow aligned with a preferred (002) orientation. This preferential orientation can be related to the re-arrangement of HAp in the presence of Hank's solution, generating a change in its orientation and promoting the preferential growth in new crystals. The development of crystallinity is guided by the mature crystallized apatite surface as shown by the alignment of the crystallographic $c$-axis along the nucleating surface, following the preferred orientation in the (002) plane.

Finally, a closer look to the mature crystallized apatite zone is shown figure $12 \mathrm{~b}$, where a higher density of crystals joined and immersed in the matrix is observed with lattice fringes between $0.322<d<0.340 \mathrm{~nm}$. This effect of crystal coalescence has been described as the formation of various calcified tissues and was referred as "crystal fusion", in which the junction and adhesion of two apatite crystals tend to form a single crystal ${ }^{51}$, in our case oriented in the c-axis direction. This effect has also been reported elsewhere, where the crystals growth along the main axis of the collagen fibrils ${ }^{38}$.

\subsubsection{Raman}

Raman spectra of BHAp and BHAp/Nagel composite samples after 0, 6, 14 and 28 days of exposure in Hank's solution are shown in figure 13a and b, respectively. Before exposure, BHAp samples showed the typical vibrational modes associated with the phosphate tetrahedral with $v_{1} \mathrm{PO}_{4}{ }^{3-}$ band close to $962 \mathrm{~cm}^{-1}$, a double $v_{2} \mathrm{PO}_{4}{ }^{3-}$ band in 430 and $444 \mathrm{~cm}^{-1}$, a triple $v_{4} \mathrm{PO}_{4}{ }^{3}$ band between 550 and $650 \mathrm{~cm}^{-1}$, respectively. Specifically for $v_{3} \mathrm{PO}_{4}{ }^{3-}$ only three bands, typical for B-type carbonated apatite are observed in 1015-1090 $\mathrm{cm}^{-1}$ spectral region ${ }^{66,67}$. Furthermore, the $\mathrm{O}-\mathrm{H}$ stretching peak can be seen at $3572 \mathrm{~cm}^{-112}$.

Before immersion, BHAp/Nagel composite samples exhibited two types of spectra labeled as 0 days "a" and "b" as shown in figure 13b. The spectrum "a" shows the same vibrational modes than those observed for pure BHAp samples. On the other hand, in the spectrum " $b$ " 
a slight contribution Si-O vibrational mode was observed in 587, 615 and $853 \mathrm{~cm}^{-1}$, which are associated with the Nagel phase identified in XRD patterns ${ }^{8}$.

After immersion in Hank's solution, similar behavior was observed for both BHAp and BHAp/Nagel composite ceramics, but the changes were more evident in samples with BG content. An increasing broadening and a continuous loss of intensity of the bands was observed after 6, 14 and 28 days of immersion, which is related to the presence of noncrystalline materials ${ }^{4}$. Specifically, vibrations of $-\mathrm{PO}_{3}$ and $-\mathrm{PO}_{2}$ groups in amorphous phosphate phases can be contributing to the broad-band between 1000 and $1300 \mathrm{~cm}^{-1}$. On the other hand, the presence of a broad-band around $1490 \mathrm{~cm}^{-1}$ can be related to carbonate ions of amorphous carbonated hydroxyapatite phase as reported in ${ }^{4}$. Moreover, in both samples after 28 days of immersion, a wide band was detected in $1070 \mathrm{~cm}^{-1}$, which has been assigned to $v_{1} \mathrm{CO}_{3}{ }^{2-}$ mode in B-Type carbonate $\mathrm{HAp}^{66}$.

For the BHAp/Nagel composite, the bands related to Si-O vibrational modes vanished after 6 days of immersion, this is expected since the mechanism of apatite formation in phases containing Si involves the dissolution and precipitation of amorphous Si-phases ${ }^{4}$.

These results evidenced the phase transformation from HAp and Nagel into a less crystalline carbohydroxyapatite or bone-like apatite. Considering the bands' linewidths at the same immersion periods for both evaluated sample compositions, it is evident that this transformation occurred faster in the BHAp/Nagel composite. A summary of the vibrational modes detected for both BHAp and BHAp/Nagel composite samples is presented in Table 2, where the reported values for stoichiometric and carbonated B-Type HAp are also included for comparative purposes.

\subsection{Degradation assessment}

The concentration of released ions after the degradation test is summarized and compared to literature values in Table 3. The effect of BG addition resulted in close to double $\mathrm{Ca}$ and $\mathrm{Na}$ dissolution in comparison with BHAp samples. Additionally, higher released Si content was observed for the BHAp/Nagel composite as expected for the BG addition. The obtained values for the analyzed species are within the range considered as no cytotoxic even in combination with other ions 52,68 . 
It is well known that dissolution of $\mathrm{Si}$ ions leads to the formation of a porous $\mathrm{SiO}_{2}$ rich layer on the surface of the powder, improving the readsorption of free ions of $\mathrm{Ca}, \mathrm{Mg}$ and $\mathrm{Si}$ in solution. As a consequence, a synergistic regulation is generated between the $\mathrm{Ca}, \mathrm{Si}$ and $\mathrm{Mg}$ ions during the dissolution process ${ }^{69}$. On the other hand, $\mathrm{Ca}$ ions tend to facilitate cell proliferation, differentiation and mineralization of human periodontal ligament cells (hPDLC), osteoblasts and stem cells. Also, extracellular Ca plays a vital role in bone remodeling by direct activation of intracellular mechanisms through the stimulation of $\mathrm{Ca}$ detection receptors in osteoblastic cells ${ }^{68}$. Mg acts on the stimulation of cell proliferation by promoting the synthesis of DNA, proteins and the regulation of $\mathrm{Mg}^{2+}$ conduction channels ${ }^{20}$. The differences in ionic release of the samples suggest variations not only in the bioactive behavior as discussed in the previous section but also in the biological response at the invitro or in-vivo level.

\section{Conclusions}

The study of biomineralization process from bovine-derived HAp and BHAp/Nagel composite allowed to complete/confirm the mechanism of apatite formation:

The formation of a hydrated amorphous matrix allows the ionic exchange between the surrounding medium and the material surface. The incorporation of $\mathrm{Ca}^{2+}$ ions into the ceramic surface leads to the formation of ACP clusters, which later develop into apatite nanocrystals. These embedded nanocrystals are randomly oriented and later coalesce, aided by $\mathrm{CO}_{3}{ }^{2-}$, forming bigger crystals with a preferred orientation to $c$-axis, the same alignment observed in natural apatite growth along collagen fibrils.

The apatite maturation process was monitored by HRTEM \& IFFT leading to the following remarks:

1) Crystals in the early stage of formation exhibited interplanar distances between 0.238 and $0.269 \mathrm{~nm}$, while mature apatite crystals reach up to $d=0.34 \mathrm{~nm}$, corresponding to the (002) HAp plane.

2) The presence of $\mathrm{Na}^{+}$in the degradation test favors the substitution of $\mathrm{PO}_{4}^{3-}$ for $\mathrm{CO}_{3}{ }^{2-}$ promoting the release of $\mathrm{Mg}^{2+}$ and $\mathrm{Ca}^{2+}$. The new cation-rich surface attracts anions from the fluid such as $\mathrm{Cl}-, \mathrm{F}-$, which in turn attracts cations and the cycle begins again, thus generating a multi-layered growth. 
3) BG addition allows the formation of nanocrystalline Nagel as a secondary phase in the 3.75 vol. \%BG sample. The apatite formation results from a coupled mechanism between the Si-containing and calcium phosphate phases. The Nagel phase contributed to an accelerated formation kinetics observed with the apatite crystallization process and better adhesion of the apatite layer to the ceramic surface observed in the inward growth of apatite into the pores.

4) After 28 days of exposure, the TEM images of the formed scale showed a highly periodic arrangement of the apatite crystals embedded in the amorphous matrix, which contrasts to the total amorphous characteristics reported for this layer at the macroscale.

\section{Acknowledgments}

The authors thank CONACYT for the financial support and the Spanish MINECO through project MAT2016-46755-R. This project was funded by CONACYT Projects 272095, 279738, 293429 and 295261 and carried out partially at CENAPROT (LN-299038) and LIDTRA (LN-295261 and LN-254119) national laboratories and LISMA. Additionally, we thank researchers Josep $\mathrm{M}^{\mathrm{a}}$ Bassas and Lluís López Conesa of to the Scientific and Technological Centers of the University of Barcelona (CCiTUB) for technical support in the XRD and TEM measurements. Finally, the thanks are extended to David Andrés FernandezBenavides and Astrid Lorena Giraldo-Betancur for overall support.

\section{References}

(1) Kokubo, T. Bioactive Glass Ceramics: Properties and Applications. Biomaterials 1991, 12 (2), 155163. https://doi.org/10.1016/0142-9612(91)90194-F.

(2) Ducheyne, P.; Qiu, Q. Bioactive Ceramics the e!Ect of Surface Reactivity on Bone Formation and Bone Cell Function. 1999, 20, 2287-2303.

(3) Müller, L.; Conforto, E.; Caillard, D.; Müller, F. A. Biomimetic Apatite Coatings-Carbonate Substitution and Preferred Growth Orientation. Biomol. Eng. 2007, 24 (5), 462-466. https://doi.org/10.1016/j.bioeng.2007.07.011.

(4) Serena, S.; Caballero, A.; De Aza, P. N.; Sainz, M. A. New Evaluation of the in Vitro Response of Silicocarnotite Monophasic Material. Ceram. Int. 2015, 41 (8), 9412-9419. https://doi.org/10.1016/j.ceramint.2015.03.319. 
(5) Sepantafar, M.; Mohammadi, H.; Maheronnaghsh, R.; Tayebi, L.; Baharvand, H. Single Phased Silicate-Containing Calcium Phosphate Bioceramics: Promising Biomaterials for Periodontal Repair. Ceram. Int. 2018. https://doi.org/10.1016/j.ceramint.2018.03.050.

(6) Wu, C.; Chang, J. A Review of Bioactive Silicate Ceramics. Biomed. Mater. 2013, 8 (3). https://doi.org/10.1088/1748-6041/8/3/032001.

(7) Rincón-López, J. A.; Hermann-Muñoz, J. A.; Giraldo-Betancur, A. L.; De Vizcaya-Ruiz, A.; AlvaradoOrozco, J. M.; Muñoz-Saldaña, J. Synthesis, Characterization and in Vitro Study of Synthetic and Bovine-Derived Hydroxyapatite Ceramics: A Comparison. Materials (Basel). 2018, 9 (3). https://doi.org/10.3390/ma11030333.

(8) Rincón-López, J. A.; Hermann-Muñoz, J. A.; Fernández-Benavides, D. A.; Giraldo-Betancur, A. L.; Alvarado-Orozco, J. M.; Muñoz-Saldaña, J. Isothermal Phase Transformations of Bovine-Derived Hydroxyapatite/Bioactive Glass: A Study by Design of Experiments. J. Eur. Ceram. Soc. 2019, 39 (4). https://doi.org/10.1016/j.jeurceramsoc.2018.11.021.

(9) Jones, J. R. Review of Bioactive Glass : From Hench to Hybrids. Acta Biomater. 2013, 9 (1), 44574486. https://doi.org/10.1016/j.actbio.2012.08.023.

(10) Vallet-regí, M. Bio-Ceramics with Clinical Applications; Vallet-Regí, M., Ed.; Wiley, 2014.

(11) Serena, S.; Sainz, M. A.; Caballero, A. Single-Phase Silicocarnotite Synthesis in the Subsystem Ca3(PO4)2-Ca2SiO4. Ceram. Int. 2014, $40 \quad$ (6), 8245-8252. https://doi.org/10.1016/j.ceramint.2014.01.022.

(12) Gomes, S.; Nedelec, J. M.; Jallot, E.; Sheptyakov, D.; Renaudin, G. Silicon Location in SilicateSubstituted Calcium Phosphate Ceramics Determined by Neutron Diffraction. Cryst. Growth Des. 2011, 11 (9), 4017-4026. https://doi.org/10.1021/cg200587s.

(13) Landi, E.; Tampieri, A.; Mattioli-Belmonte, M.; Celotti, G.; Sandri, M.; Gigante, A.; Fava, P.; Biagini, G. Biomimetic Mg- and Mg,CO3-Substituted Hydroxyapatites: Synthesis Characterization and in Vitro Behaviour. J. Eur. Ceram. Soc. 2006, $26 \quad$ (13), 2593-2601. https://doi.org/10.1016/j.jeurceramsoc.2005.06.040.

(14) Furko, M.; Havasi, V.; Kónya, Z.; Grünewald, A.; Detsch, R.; Boccaccini, A. R.; Balázsi, C. Development and Characterization of Multi-Element Doped Hydroxyapatite Bioceramic Coatings on Metallic Implants for Orthopedic Applications. Boletín la Soc. Española Cerámica y Vidr. 2017. https://doi.org/https://doi.org/10.1016/j.bsecv.2017.09.003.

(15) Fielding, G. A.; Bandyopadhyay, A.; Bose, S. Effects of Silica and Zinc Oxide Doping on Mechanical and Biological Properties of 3D Printed Tricalcium Phosphate Tissue Engineering Scaffolds. Dent. Mater. 2012, 28 (2), 113-122. https://doi.org/10.1016/j.dental.2011.09.010.

(16) Boanini, E.; Torricelli, P.; Sima, F.; Axente, E.; Fini, M.; Mihailescu, I. N.; Bigi, A. Strontium and Zoledronate Hydroxyapatites Graded Composite Coatings for Bone Prostheses. J. Colloid Interface Sci. 2015, 448, 1-7. https://doi.org/10.1016/j.jcis.2015.01.088. 
(17) Reffitt, D. M.; Jugdaohsingh, R.; Thompson, R. P. H.; Powell, J. J. Silicic Acid: Its Gastrointestinal Uptake and Urinary Excretion in Man and Effects on Aluminium Excretion. J. Inorg. Biochem. 1999, 76 (2), 141-147. https://doi.org/10.1016/S0162-0134(99)00126-9.

(18) Padilla, S.; Román, J.; Sánchez-salcedo, S.; M., V.-R. Hydroxyapatite / SiO2 - CaO - P2O5 Glass Materials: In Vitro Bioactivity and Biocompatibility. Acta Biomater. 2006, No. June, 331-342. https://doi.org/10.1016/j.actbio.2006.01.006.

(19) Gaharwar, A. K.; Mihaila, S. M.; Swami, A.; Patel, A.; Sant, S.; Reis, R. L.; Marques, A. P.; Gomes, M. E.; Khademhosseini, A. Bioactive Silicate Nanoplatelets for Osteogenic Differentiation of Human Mesenchymal Stem Cells. Adv. Mater. 2013, 25 (24), 3329-3336. https://doi.org/10.1002/adma.201300584.

(20) Zreiqat, H.; Howlett, C. R.; Zannettino, A.; Evans, P.; Schulze-Tanzil, G.; Knabe, C.; Shakibaei, M. Mechanisms of Magnesium-Stimulated Adhesion of Osteoblastic Cells to Commonly Used Orthopaedic Implants. J. Biomed. Mater. Res. 2002, $62 \quad$ (2), 175-184. https://doi.org/10.1002/jbm.10270.

(21) Barakat, N. A. M.; Khil, M. S.; Omran, A. M.; Sheikh, F. A.; Kim, H. Y. Extraction of Pure Natural Hydroxyapatite from the Bovine Bones Bio Waste by Three Different Methods. J. Mater. Process. Technol. 2009, 209 (7), 3408-3415. https://doi.org/10.1016/j.jmatprotec.2008.07.040.

(22) Piña, C.; Palma, B.; Munguía, N.; Piña, C.; Palma, B.; Munguía, N. Material Properties of Inorganic Bovine Cancellous Bovine : Nukbone. 2006, 221, 1-4. https://doi.org/10.1063/1.2356454.

(23) Kattimani, V. S.; Kondaka, S.; Lingamaneni, K. P. Hydroxyapatite--Past, Present, and Future in Bone Regeneration. Bone Tissue Regen. Insights 2016, 7, BTRI.S36138. https://doi.org/10.4137/BTRI.S36138.

(24) Maçon, A. L. B.; Kim, T. B.; Valliant, E. M.; Goetschius, K.; Brow, R. K.; Day, D. E.; Hoppe, A.; Boccaccini, A. R.; Kim, I. Y.; Ohtsuki, C.; et al. A Unified in Vitro Evaluation for Apatite-Forming Ability of Bioactive Glasses and Their Variants. J. Mater. Sci. Mater. Med. 2015, 26 (2), 1-10. https://doi.org/10.1007/s10856-015-5403-9.

(25) Kim, H. M.; Himeno, T.; Kokubo, T.; Nakamura, T. Process and Kinetics of Bonelike Apatite Formation on Sintered Hydroxyapatite in a Simulated Body Fluid. Biomaterials 2005, 26 (21), 43664373. https://doi.org/10.1016/j.biomaterials.2004.11.022.

(26) Kumar, A.; Murugavel, S.; Aditya, A.; Boccaccini, A. R. Mesoporous 45S5 Bioactive Glass: Synthesis,: In Vitro Dissolution and Biomineralization Behavior. J. Mater. Chem. B 2017, 5 (44), 8786-8798. https://doi.org/10.1039/c7tb01738c.

(27) Gandolfi, M. G.; Ciapetti, G.; Taddei, P.; Perut, F.; Tinti, A.; Cardoso, M. V.; Van Meerbeek, B.; Prati, C. Apatite Formation on Bioactive Calcium-Silicate Cements for Dentistry Affects Surface Topography and Human Marrow Stromal Cells Proliferation. Dent. Mater. 2010, 26 (10), 974-992. https://doi.org/10.1016/j.dental.2010.06.002. 
(28) Boccaccini, A. R.; Chen, Q.; Lefebvre, L.; Gremillard, L.; Chevalier, J. Sintering, Crystallisation and

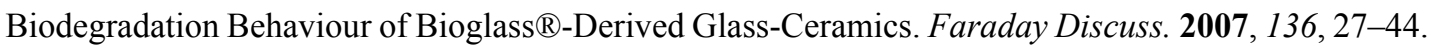
https://doi.org/10.1039/b616539g.

(29) Zadpoor, A. A. Relationship between in Vitro Apatite-Forming Ability Measured Using Simulated Body Fl Uid and in Vivo Bioactivity of Biomaterials. Mater. Sci. Eng. C 2014, 35, 134-143. https://doi.org/10.1016/j.msec.2013.10.026.

(30) Ã, T. K.; Takadama, H. How Useful Is SBF in Predicting in Vivo Bone Bioactivity ? \$. 2006, 27, $2907-$ 2915. https://doi.org/10.1016/j.biomaterials.2006.01.017.

(31) Kim, H.-M.; Himeno, T.; Kawashita, M.; Kokubo, T.; Nakamura, T. The Mechanism of Biomineralization of Bone-like Apatite on Synthetic Hydroxyapatite: An in Vitro Assessment. $J$. R. Soc. Interface 2004, 1 (1), 17-22. https://doi.org/10.1098/rsif.2004.0003.

(32) Hench, L. L. Bioactive Materials. Ceram. Int. 1996, 8842 (95), 493-507.

(33) Takadama, H.; Kim, H. M.; Kokubo, T.; Nakamura, T. Mechanism of Biomineralization of Apatite on a Sodium Silicate Glass: TEM-EDX Study in Vitro. Chem. Mater. 2001, 13 (3), 1108-1113. https://doi.org/10.1021/cm0008718.

(34) Vallet-Regí, María; Izquierdo-Barba, I. S. A. J. Influence of P 2 O 5 on Crystallinity of Apatite Formed in Vitro on Surface of Bioactive Glasses. 1999.

(35) Leng, Y.; Chen, J.; Qu, S. TEM Study of Calcium Phosphate Precipitation on HA/TCP Ceramics. Biomaterials 2003, 24 (13), 2125-2131. https://doi.org/10.1016/S0142-9612(03)00036-X.

(36) Takadama, H.; Kim, H. M.; Miyaji, F.; Kokubo, T.; Nakamura, T. Mechanism of Apatite Formation Induced by Silanol Groups - TEM Observation. J. Ceram. Soc. Japan 2000, 108 (2), 118-121. https://doi.org/10.2109/jcersj.108.1254_118.

(37) He, G.; Dahl, T.; Veis, A.; George, A. Nucleation of Apatite Crystals in Vitro by Self-Assembled Dentin Matrix Protein 1. Nat. Mater. 2003, 2 (8), 552-558. https://doi.org/10.1038/nmat945.

(38) Dey, A.; Bomans, P. H. H.; Müller, F. A.; Will, J.; Frederik, P. M.; De With, G.; Sommerdijk, N. A. J. M. The Role of Prenucleation Clusters in Surface-Induced Calcium Phosphate Crystallization. Nat. Mater. 2010, 9 (12), 1010-1014. https://doi.org/10.1038/nmat2900.

(39) Wang, Y.; Azaïs, T.; Robin, M.; Vallée, A.; Catania, C.; Legriel, P.; Pehau-Arnaudet, G.; Babonneau, F.; Giraud-Guille, M. M.; Nassif, N. The Predominant Role of Collagen in the Nucleation, Growth, Structure and Orientation of Bone Apatite. Nat. Mater. 2012, 11 (8), 724-733. https://doi.org/10.1038/nmat3362.

(40) Aizawa, M.; Porter, A. E.; Best, S. M.; Bonfield, W. Ultrastructural Observation of Single-Crystal $\begin{array}{llllll}\text { Apatite } & \text { Fibres. } & \text { Biomaterials } & \text { 2005, } & 26 & \text { (17), }\end{array}$ https://doi.org/10.1016/j.biomaterials.2004.09.044.

(41) Zhuang, Z.; Miki, T.; Yumoto, M.; Konishi, T.; Aizawa, M. Ultrastructural Observation of 
1

2

3

4

5

6

7

8

9

Hydroxyapatite Ceramics with Preferred Orientation to A-Plane Using High-Resolution Transmission Electron Microscopy. Procedia Eng. 2012, 36, 121-127. https://doi.org/10.1016/j.proeng.2012.03.019.

(42) Xin, R.; Leng, Y.; Wang, N. In Situ TEM Examinations of Octacalcium Phosphate to Hydroxyapatite Transformation. J. Cryst. Growth 2006, $289 \quad$ (1), 339-344 https://doi.org/10.1016/j.jcrysgro.2005.11.010.

(43) Xin, R.; Zhang, Q.; Gao, J. Identification of the Wollastonite Phase in Sintered 45S5 Bioglass and Its Effect on in Vitro Bioactivity. J. Non. Cryst. Solids 2010, 356 (23-24), 1180-1184. https://doi.org/10.1016/j.jnoncrysol.2010.03.010.

(44) AG., S. https://www.schott.com/epackaging/english/bioactive/products/cosmetics.html.

(45) ISO. ISO/FDIS 23317: Implants for Surgery-In Vitro Evaluation for Apatite-Forming Ability of Implant Materials; 2007; p 42. https://doi.org/ISO/FDIS 22000.

(46) Iso. ISO 10993: Biological Evaluation of Medical Devices - Part 14: Identification and Quantification of Degradation Products from Ceramics; 2002.

(47) Vandiver, J.; Dean, D.; Patel, N.; Botelho, C.; Best, S.; Santos, J. D.; Lopes, M. A.; Bonfield, W.; Ortiz, C. Silicon Addition to Hydroxyapatite Increases Nanoscale Electrostatic, van Der Waals, and Adhesive Interactions. J. Biomed. Mater. Res. Part A 2006. https://doi.org/10.1002/jbm.a.

(48) Yu, H.; Liu, K.; Zhang, F.; Wei, W.; Chen, C.; Huang, Q. Microstructure and in Vitro Bioactivity of Silicon-Substituted Hydroxyapatite. Silicon 2017, 9 (4), 543-553. https://doi.org/10.1007/s12633-0159298-3.

(49) Widmer, R.; Gfeller, F.; Armbruster, T. Structural and Crystal Chemical Investigation of Intermediate Phases in the System Ca2SiO4-Ca3(PO4)2-CaNaPO4. J. Am. Ceram. Soc. 2015, 98 (12), 3956-3965. https://doi.org/10.1111/jace.13850.

(50) T, B. W.; Pasteris, J. D. A Mineralogical Perspective on the Apatite in Bone. 2005, 25, $131-143$. https://doi.org/10.1016/j.msec.2005.01.008.

(51) Rey, C.; Combes, C.; Drouet, C.; Sfihi, H.; Barroug, A. Physico-Chemical Properties of Nanocrystalline Apatites: Implications for Biominerals and Biomaterials. Mater. Sci. Eng. C 2007, 27 (2), 198-205. https://doi.org/10.1016/j.msec.2006.05.015.

(52) Sang Cho, J.; Um, S. H.; Su Yoo, D.; Chung, Y. C.; Hye Chung, S.; Lee, J. C.; Rhee, S. H. Enhanced Osteoconductivity of Sodium-Substituted Hydroxyapatite by System Instability. J. Biomed. Mater. Res. - Part B Appl. Biomater. 2014, 102 (5), 1046-1062. https://doi.org/10.1002/jbm.b.33087.

(53) Peroos, S.; Du, Z.; De Leeuw, N. H. A Computer Modelling Study of the Uptake, Structure and Distribution of Carbonate Defects in Hydroxy-Apatite. Biomaterials 2006, 27 (9), 2150-2161. https://doi.org/10.1016/j.biomaterials.2005.09.025.

(54) Lala, S.; Ghosh, M.; Das, P. K.; Das, D.; Kar, T.; Pradhan, S. K. Magnesium Substitution in Carbonated Hydroxyapatite: Structural and Microstructural Characterization by Rietveld's Refinement. Mater. 
Chem. Phys. 2016, 170, 319-329. https://doi.org/10.1016/j.matchemphys.2015.12.058.

(55) Elliott, J. C.; Wilson, R. M.; Dowker, S. E. P. APATITE STRUCTURES. 2002, 45 (c), 172-181.

(56) Liu, Q.; Huang, S.; Matinlinna, J. P.; Chen, Z.; Pan, H. Review Article Insight into Biological Apatite : Physiochemical Properties and Preparation Approaches. 2013, 2013.

(57) Akram, M.; Ahmed, R.; Shakir, I.; Ibrahim, W. A. W.; Hussain, R. Extracting Hydroxyapatite and Its Precursors from Natural Resources. J. Mater. Sci. 2014, 49 (4), 1461-1475. https://doi.org/10.1007/s10853-013-7864-x.

(58) Müller, F. A.; Müller, L.; Caillard, D.; Conforto, E. Preferred Growth Orientation of Biomimetic Apatite Crystals. J. Cryst. Growth 2007, $304 \quad$ (2), 464-471. https://doi.org/10.1016/j.jcrysgro.2007.03.014.

(59) Nakano, T.; Kaibara, K.; Tabata, Y.; Nagata, N.; Enemoto, S.; Marukawa, E.; Umakoshi, Y. Unique Alignment and Texture of Biological Apatite Crystallites in Typical Calcified Tissues Analyzed by Microbeam X-Ray Diffractometer System. Bone 2002, 31 (4), 479-487.

(60) Aizawa, M.; Matsuura, T.; Zhuang, Z. Syntheses of Single-Crystal Apatite Particles with Preferred Orientation to the a- and c-Axes as Models of Hard Tissue and Their Applications. Biol. Pharm. Bull. 2013, 36 (11), 1654-1661. https://doi.org/10.1248/bpb.b13-00439.

(61) Aizawa, M.; Ueno, H.; Itatani, K.; Okada, I. Syntheses of Calcium-Deficient Apatite Fibres by a Homogeneous Precipitation Method and Their Characterizations. J. Eur. Ceram. Soc. 2006, 26 (4-5), 501-507. https://doi.org/10.1016/j.jeurceramsoc.2005.07.007.

(62) Eanes, E. D.; Termine, J. D.; Nylen, M. U. An Electron Microscopic Study of the Formation of Amorphous Calcium Phosphate and Its Transformation to Crystalline Apatite. Calcif. Tissue Res. 1973, 12 (1), 143-158. https://doi.org/10.1007/BF02013730.

(63) Liao, S.; Watari, F.; Xu, G.; Ngiam, M.; Ramakrishna, S.; Chan, C. K. Morphological Effects of Variant Carbonates in Biomimetic Hydroxyapatite. Mater. Lett. 2007, 61 (17), 3624-3628. https://doi.org/10.1016/j.matlet.2006.12.007.

(64) Zhong, J. P.; Greenspan, D. C.; Feng, J. W. A Microstructural Examination of Apatite Induced by Bioglass ${ }^{\circledR}$ in Vitro. J. Mater. Sci. Mater. Med. 2002, 13 (3), 321-326. https://doi.org/10.1023/A:1014075320987.

(65) Hench, L. L. Bioceramics. Stress Int. J. Biol. Stress 1998, 28, 1705-1728. https://doi.org/10.1111/j.1151-2916.1998.tb02540.x.

(66) Penel, G.; Leroy, G.; Rey, C.; Bres, E. MicroRaman Spectral Study of the PO4 and CO3 Vibrational Modes in Synthetic and Biological Apatites. Calcif. Tissue Int. 1998, 63 (6), 475-481. https://doi.org/10.1007/s002239900561.

(67) Antonakos, A.; Liarokapis, E.; Leventouri, T. Micro-Raman and FTIR Studies of Synthetic and Natural Apatites. Biomaterials 2007, 28 (19), 3043-3054. https://doi.org/10.1016/j.biomaterials.2007.02.028. 
(68) Zhang, M.; Chen, X.; Pu, X.; Liao, X.; Huang, Z.; Yin, G. Dissolution Behavior of $\mathrm{CaO}-\mathrm{MgO}-\mathrm{SiO} 2-$ based Multiphase Bioceramic Powders and Effects of the Released Ions on Osteogenesis. J. Biomed. Mater. Res. Part A 2017, No. 24, 1-36.

(69) Saravanapavan, P.; Jones, J. R.; Pryce, R. S.; Hench, L. L. Bioactivity of Gel - Glass Powders in the CaO-SiO 2 System : A Comparison with Ternary ( CaO-P 2 O 5 -SiO 2 ) and Quaternary Glasses ( $\mathrm{SiO}$ 2 -CaO-P 2 O 5 -Na 2 O ). 2002, 17-19. 


\section{Figure Caption}

Figure 1. Morphological changes on BHAp ceramics surface before $(a, e)$ and after $6(b, f)$, $14(\mathrm{c}, \mathrm{g})$ and $28(\mathrm{~d}, \mathrm{~h})$ days of exposure to Hank's solution.

Figure 2. Morphological changes on BHAp/Nagel composite ceramics surface before (a,e) and after $6(\mathrm{~b}, \mathrm{f}), 14(\mathrm{c}, \mathrm{g})$ and $28(\mathrm{~d}, \mathrm{~h})$ days of exposure to Hank's solution.

Figure 3. Cross-section micrographs showing the apatite layer thickness and composition after 14 and 28 days of immersion in Hank's solution of $(a, b)$ BHAp and (c,d) BHAp/Nagel composite ceramics. The arrows indicate the apatite growing into the pores.

Figure 4. XRD pattern plotted between $20-522 \theta\left(^{\circ}\right)$ of a) BHAp and b) BHAp/Nagel composite ceramics after $0,6,14$ and 28 days of immersion.

Figure 5a. High resolution TEM images, Inverse FFT (I) and FFT (II) of BHAp before bioactivity test.

Figure 5b. SAED pattern of BHAp before bioactivity test.

Figure 6a. High resolution TEM, Inverse FFT (I) and FFT (II) images of BHAp/Nagel composite before bioactivity test.

Figure 6b. SAED pattern of a nanocrystalline region of BHAp/Nagel composite before bioactivity test.

Figure 7. High resolution TEM images of BHAp after 6 days of exposure in Hank's solution, showing in a) morphology of the particles composed by b) crystalline zones (inset FFT image) and c) an amorphous matrix.

Figure 8. High resolution TEM images showing a) BHAp/Nagel composite particles after 6 days of immersion and b) closer look to the amorphous matrix. I and II show FFT images and profile of the marked zones.

Figure 9. High resolution TEM of a) BHAp particles after 28 days of exposure, b) zoom on the elongated crystals c) closer look to the interface between amorphous matrix and crystalline zone (inset FFT).

Figure 10. a,b) High resolution TEM images of different areas of BHAp particles after 28 days of immersion with apatite nanocrystals embedded. II and III show FFT images and IFFT of the marked zone I.

Figure 11. High resolution TEM of different areas of BHAp/Nagel composite particles after 28 days of exposure.

Figure 12. a,b) High resolution TEM images of different areas of BHAp/Nagel composite particles after 28 days of immersion. I-II show FFT images of the marked zones, and III corresponds to IFFT of region I.

Figure 13. Raman spectra of a) BHAp and b) BHAp/Nagel composite after different periods of immersion in Hank's solution. 


\section{Table caption}

Table 1. Lattice parameters, crystallite size, cell volume, $\mathrm{Ca} / \mathrm{P}$ ratio, goodness coefficient $\left(\boldsymbol{\chi}^{2}\right)$ and structure factor $\left(\mathbf{R}_{\mathbf{f}}\right)$ obtained from Rietveld refinement, for BHAp and BHAp/Nagel composite samples before and after immersion

Table 2. Comparison of Raman band assignments reported for stoichiometric HAp, carbonated HAp Type B, and experimental values from BHAp and BHAp/Nagel composite after $0,6,14$ and 28 days of immersion in Hank's solution

Table 3. Ionic concentrations in the soaking solution before and after the degradation test. The concentrations considered cytotoxic are included for comparative purposes. 


\title{
For Table of Contents Use Only
}

\section{Preferred growth orientation of apatite crystals on biological hydroxyapatite enriched with bioactive glass: a biomimetic behavior}

\author{
July Andrea Rincón-López ${ }^{1}$, Jennifer Andrea Hermann-Muñoz ${ }^{1}$, Núria Cinca-Luis ${ }^{2}$, \\ Beatriz Garrido-Domiguez ${ }^{2}$, Irene García-Cano ${ }^{2}$, Jose Maria Guilemany-Casadamon ${ }^{2}$, \\ Juan Manuel Alvarado-Orozco ${ }^{3,4^{*}}$, Juan Muñoz-Saldaña ${ }^{1^{*}}$ \\ ${ }^{1}$ Centro de Investigación y de Estudios Avanzados del IPN, Unidad Querétaro, Libramiento Norponiente \\ \#2000, Querétaro, Qro., C.P. 76230, México. \\ ${ }^{2}$ Centro de Proyección Térmica (CPT). Dpt. Ciència dels Materials i Química Física, Universitat de \\ Barcelona, c/Martí i Franquès 1, E-08028 Barcelona, Spain. \\ ${ }^{3}$ Centro de Ingeniería y Desarrollo Industrial, Av. Playa Pie de la Cuesta No. 702, Desarrollo San Pablo, \\ Querétaro, Qro., C.P. 76125, México. \\ ${ }^{4}$ Consorcio de Manufactura Aditiva, CONMAD, Av. Pie de la Cuesta 702, Desarrollo San Pablo, \\ Querétaro, México. \\ *Corresponding authors: juan.alvarado@,cidesi.edu.mx,jmunoz@,cinvestav.mx
}

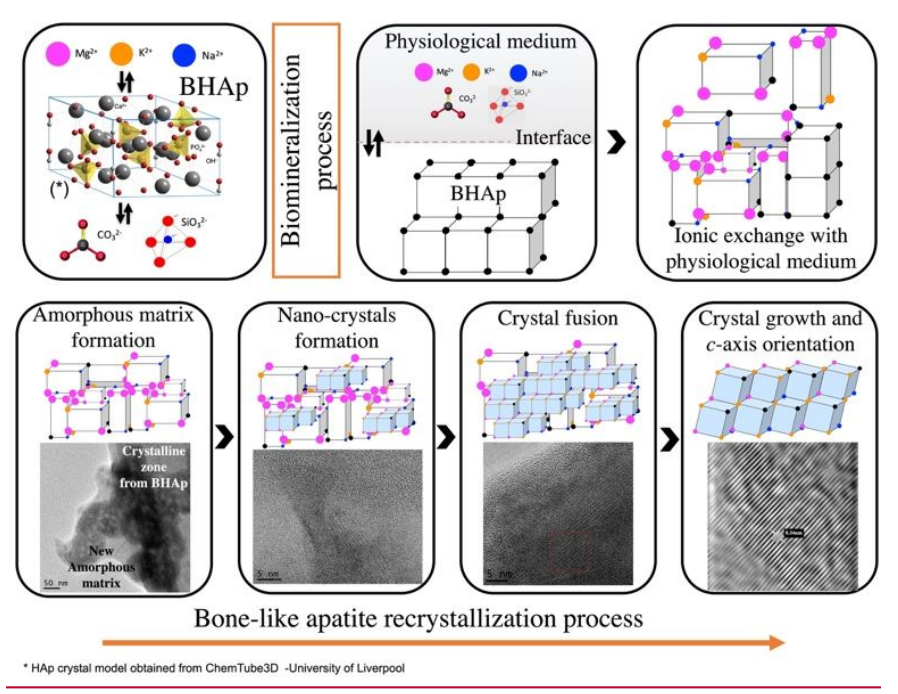

This contribution presents morphological, structural and chemical transformations during the biomineralization process of BHAp enriched with Vitryxx ${ }^{\circledR}$ bioactive glass, where the mechanism of mineral matrix formation at the nano- and micro-scale is discussed. A highly periodic arrangement of the apatite crystals at the local level was observed with an accelerated apatite crystallization process due to the presence of Nagel phase. 


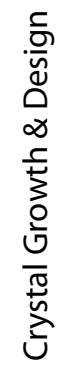
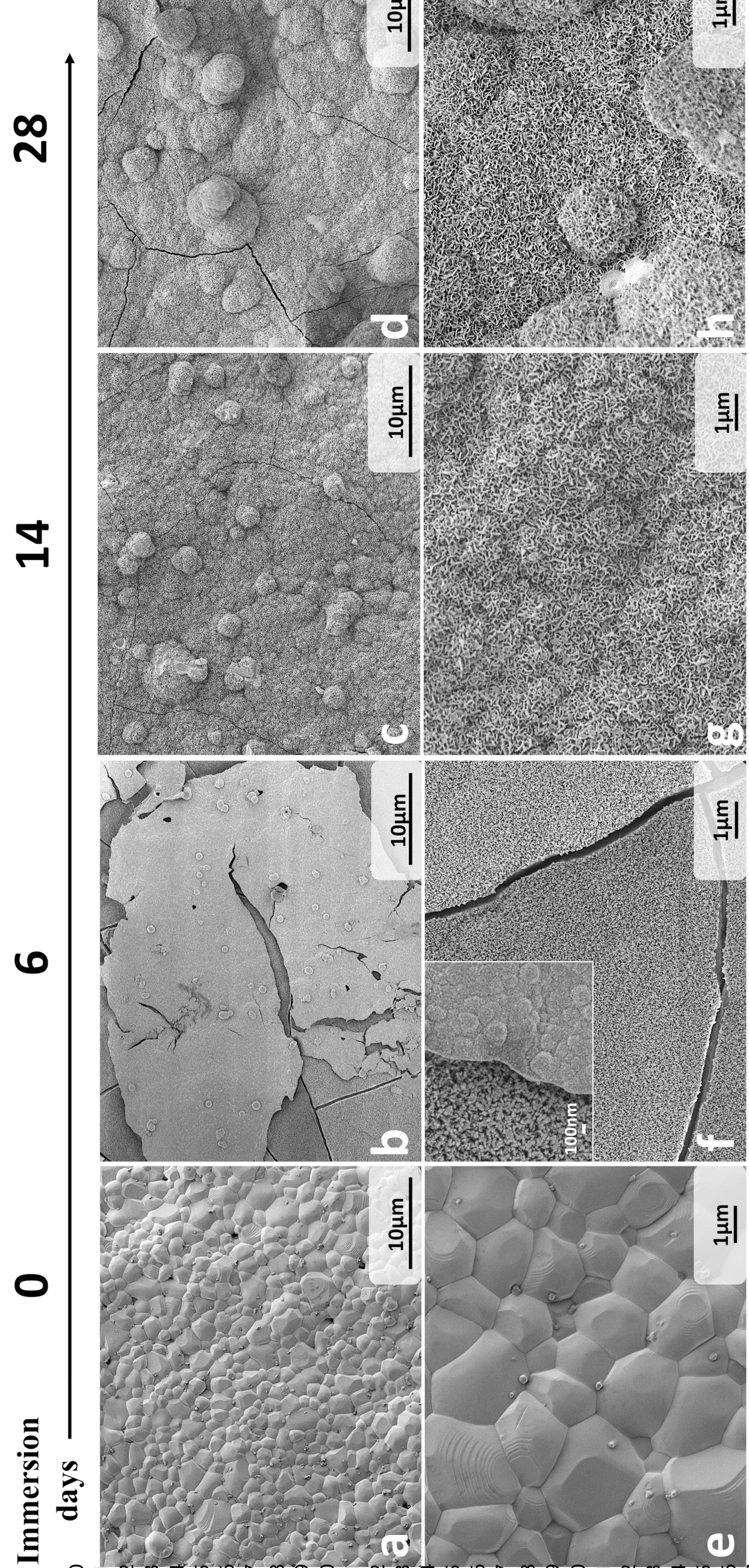

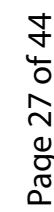




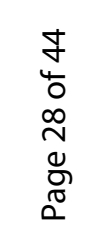

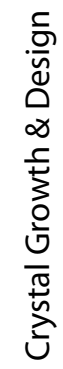

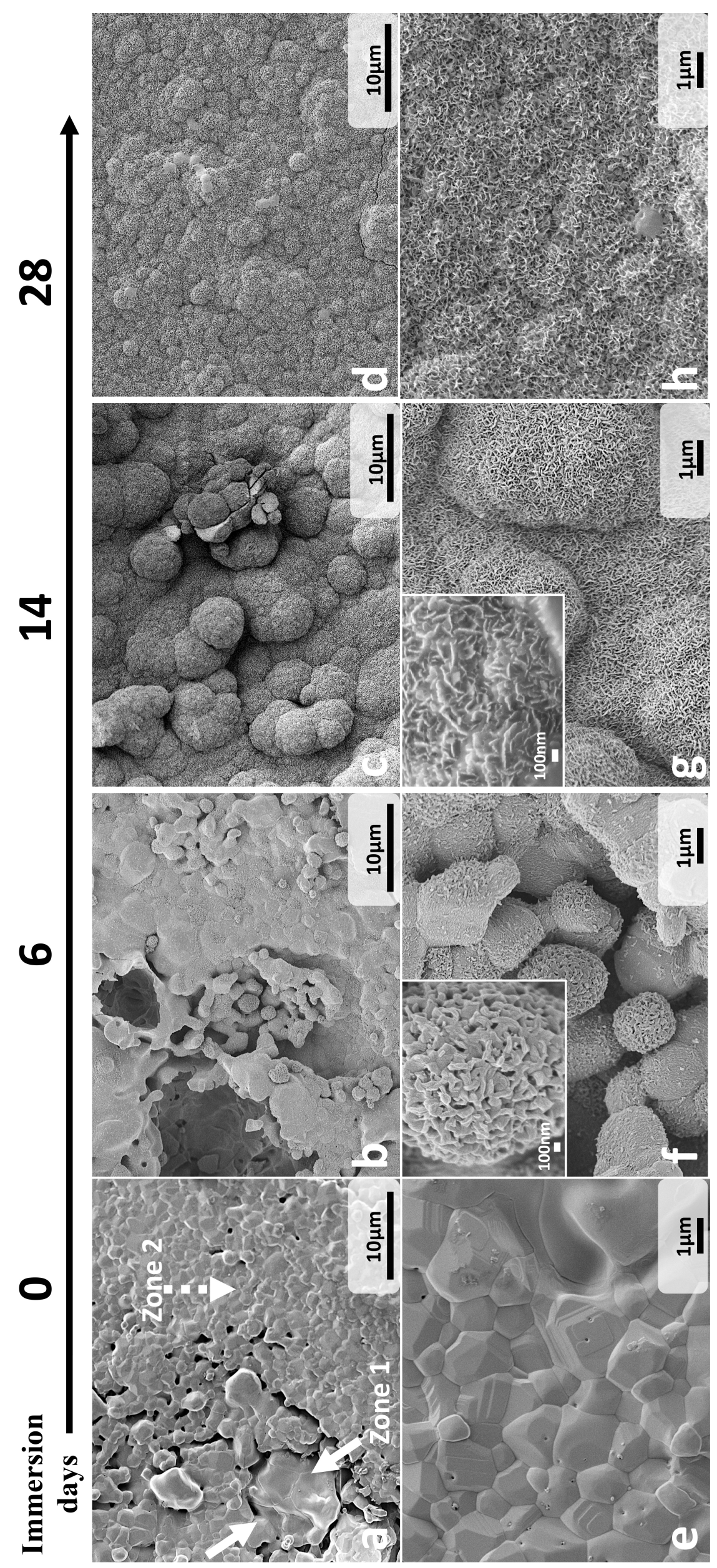

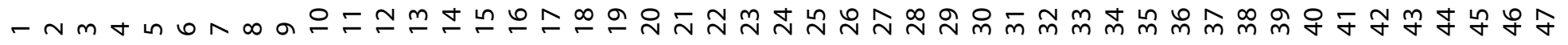



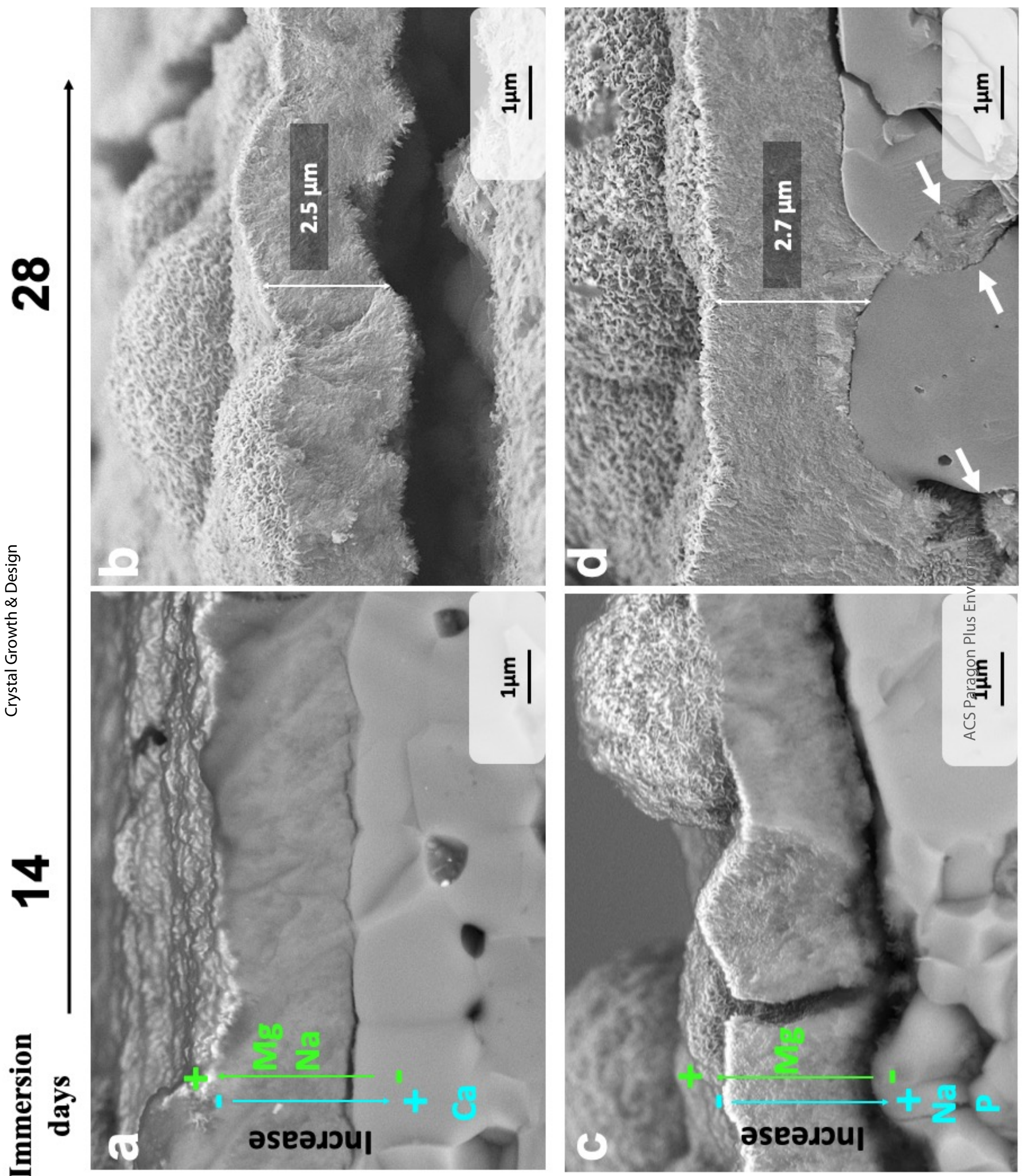

\section{dVHg}

วฺ!soduos [ə8ిe N/dVHg

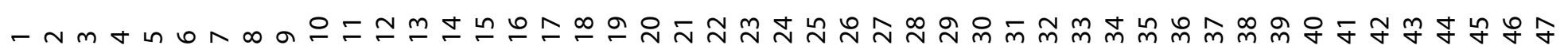




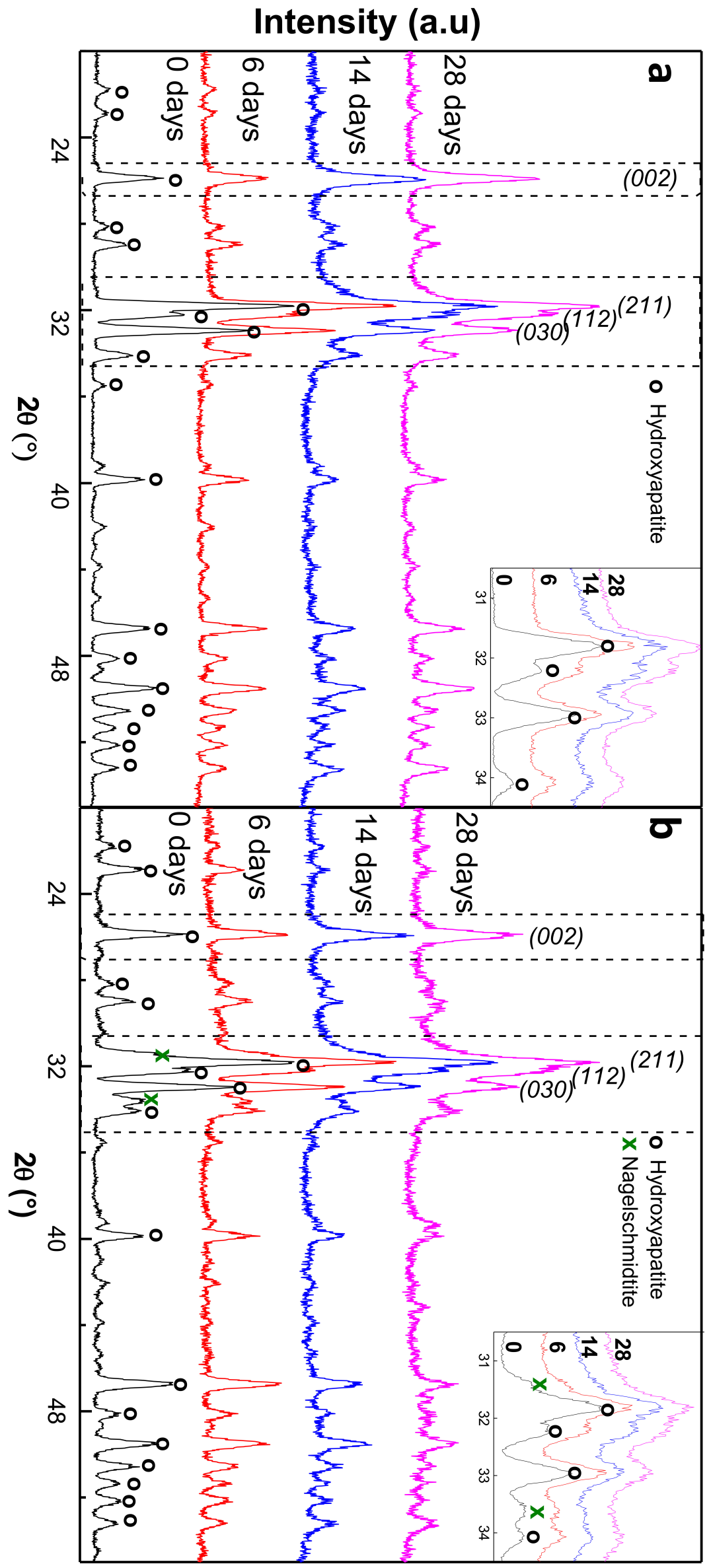




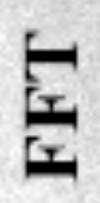

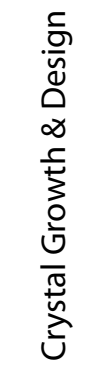

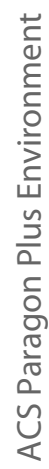
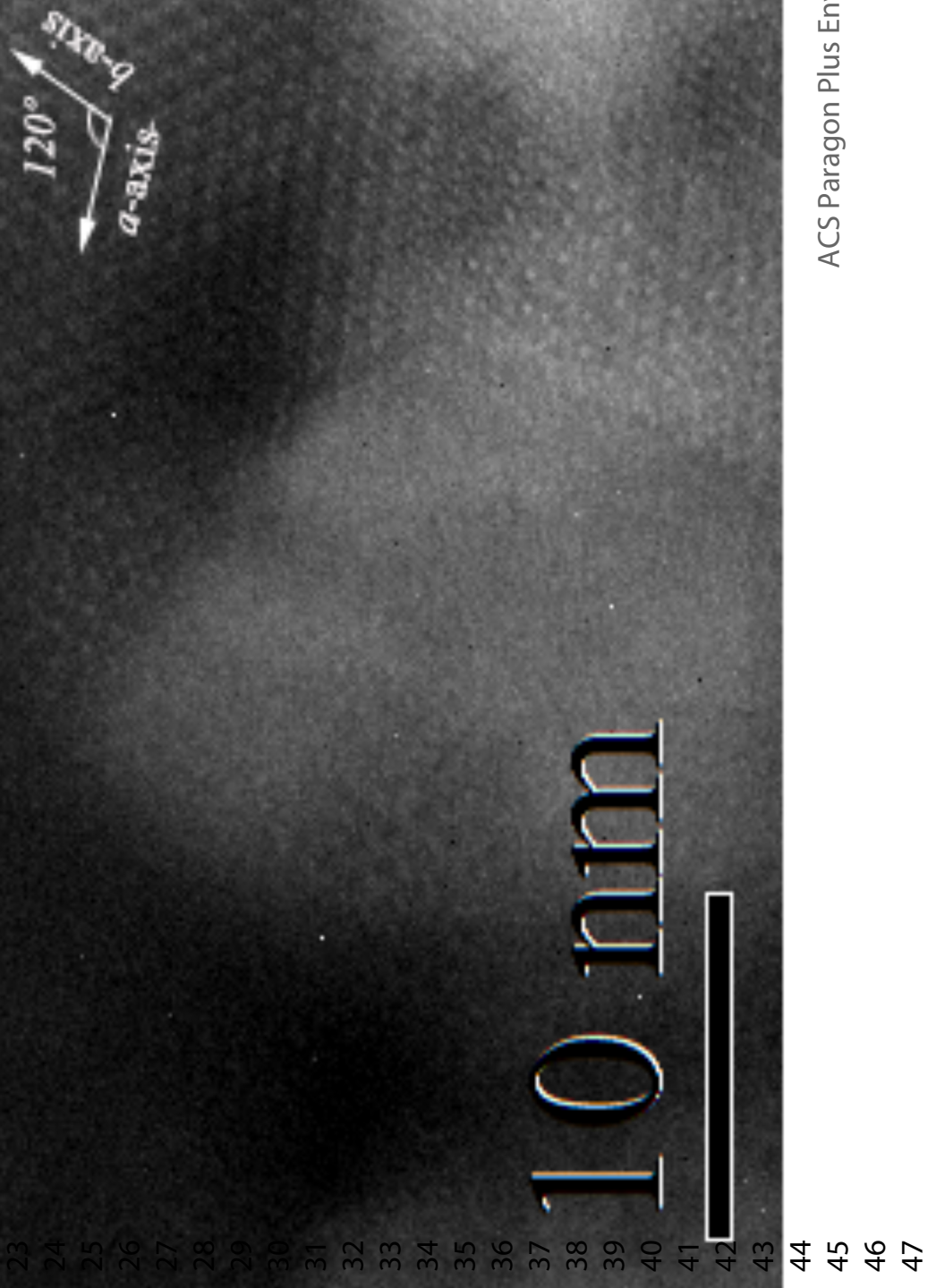


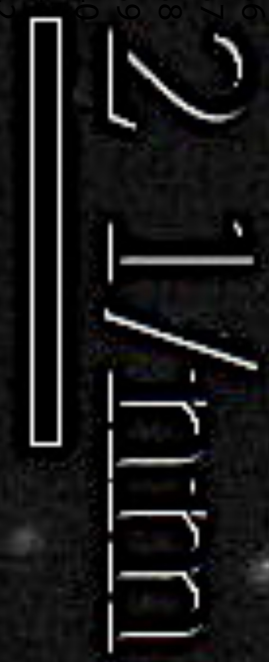




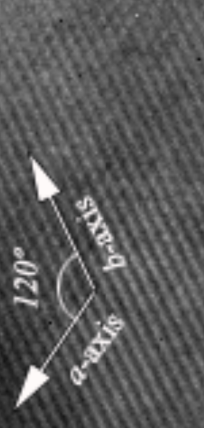

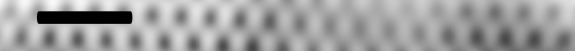

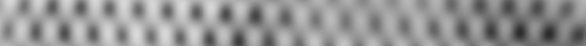

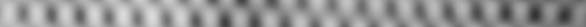

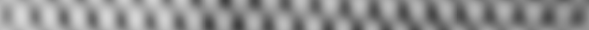

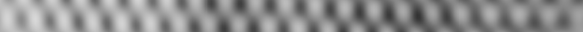

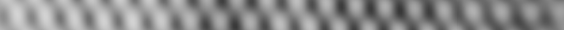

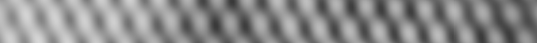
. .

\section{(1)}

(1)

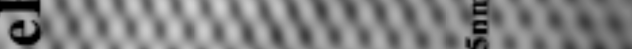

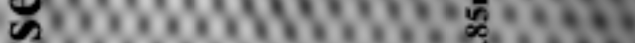

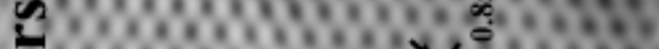

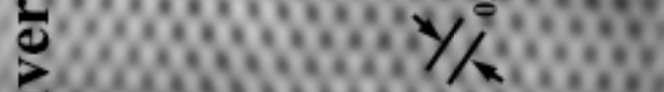




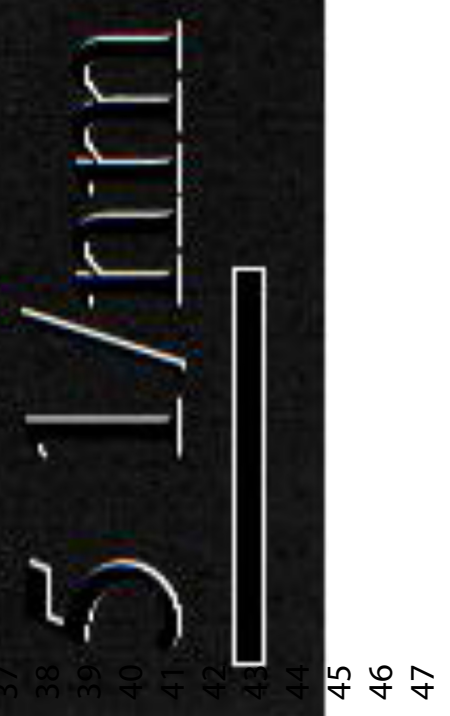




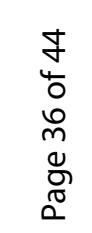

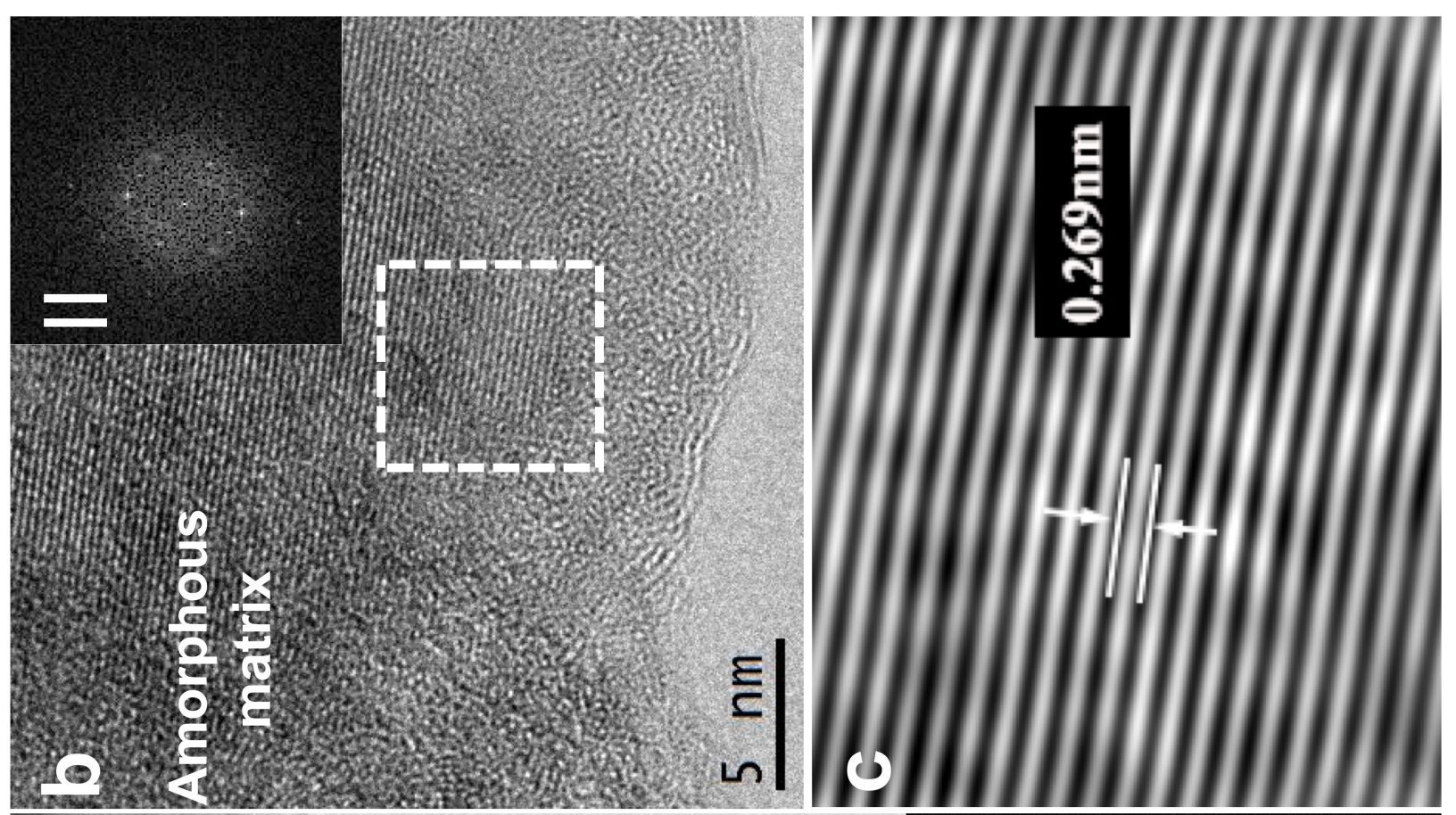

$\frac{5}{5}$
$\frac{5}{0}$
$\infty$
$\frac{5}{5}$
$\frac{0}{3}$
$\frac{0}{\pi}$
$\frac{\pi}{n}$
$\frac{\lambda}{U}$

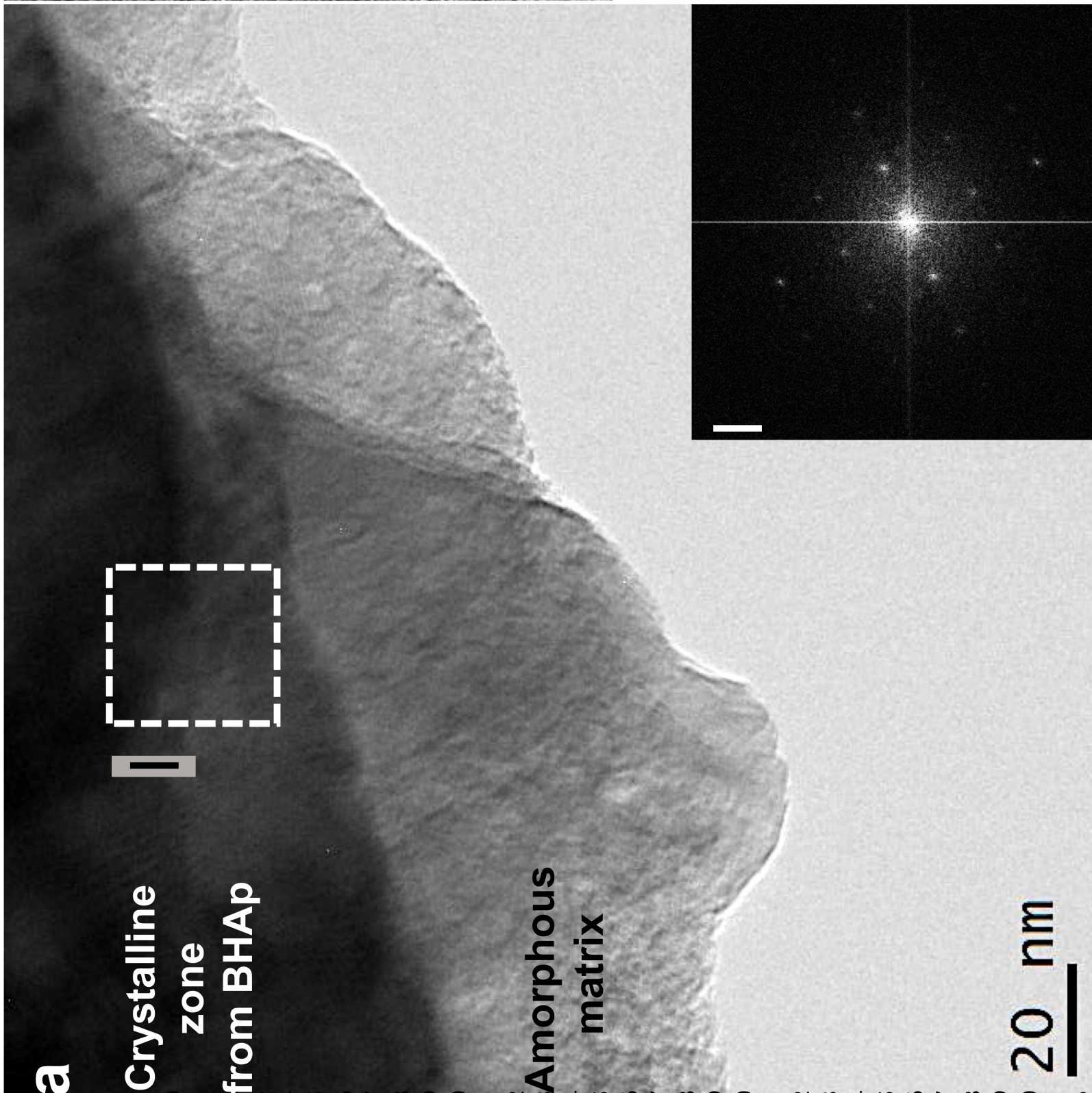

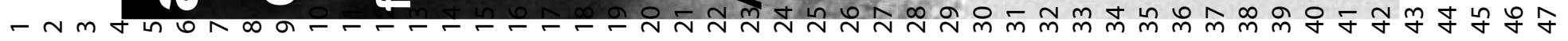




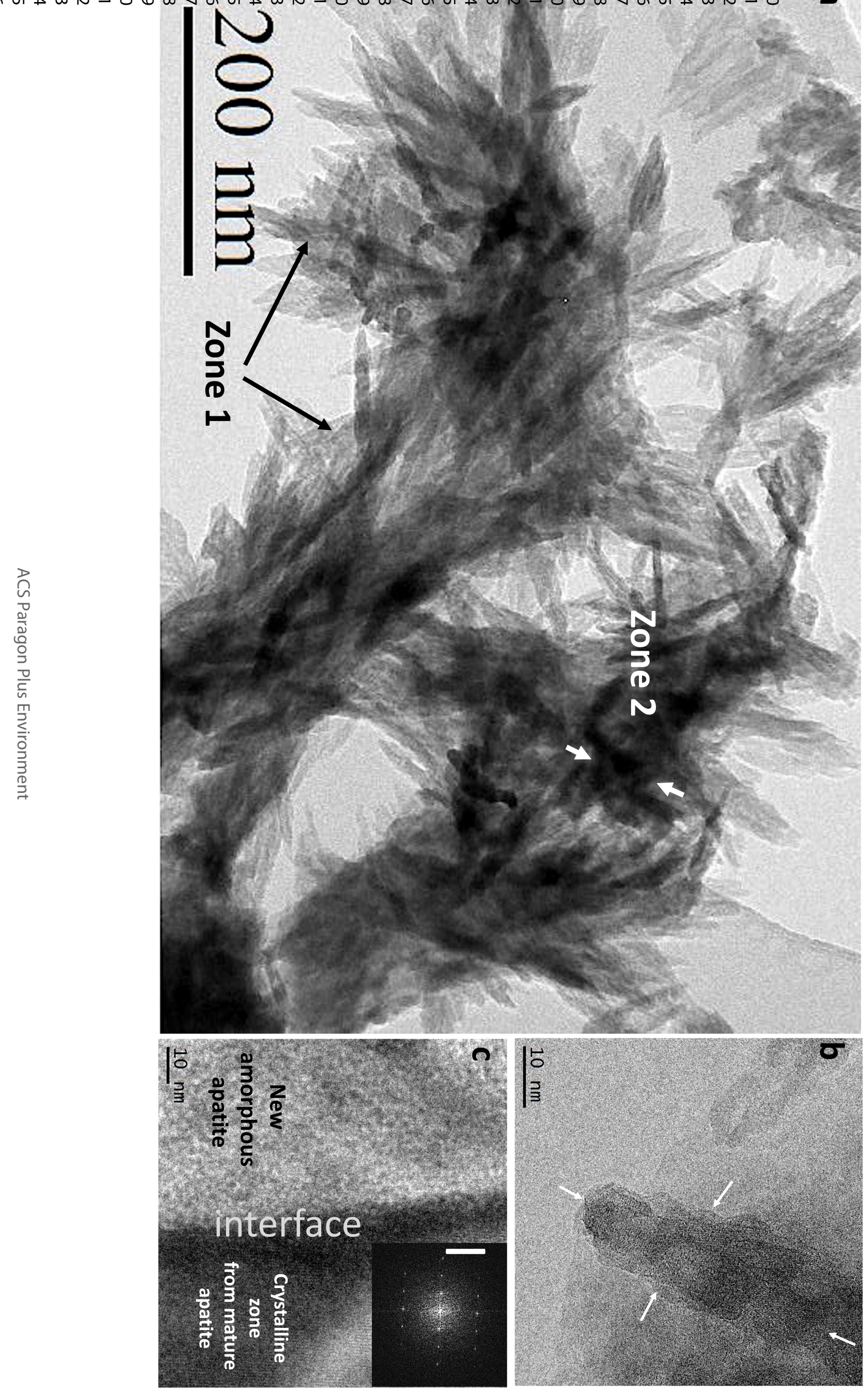




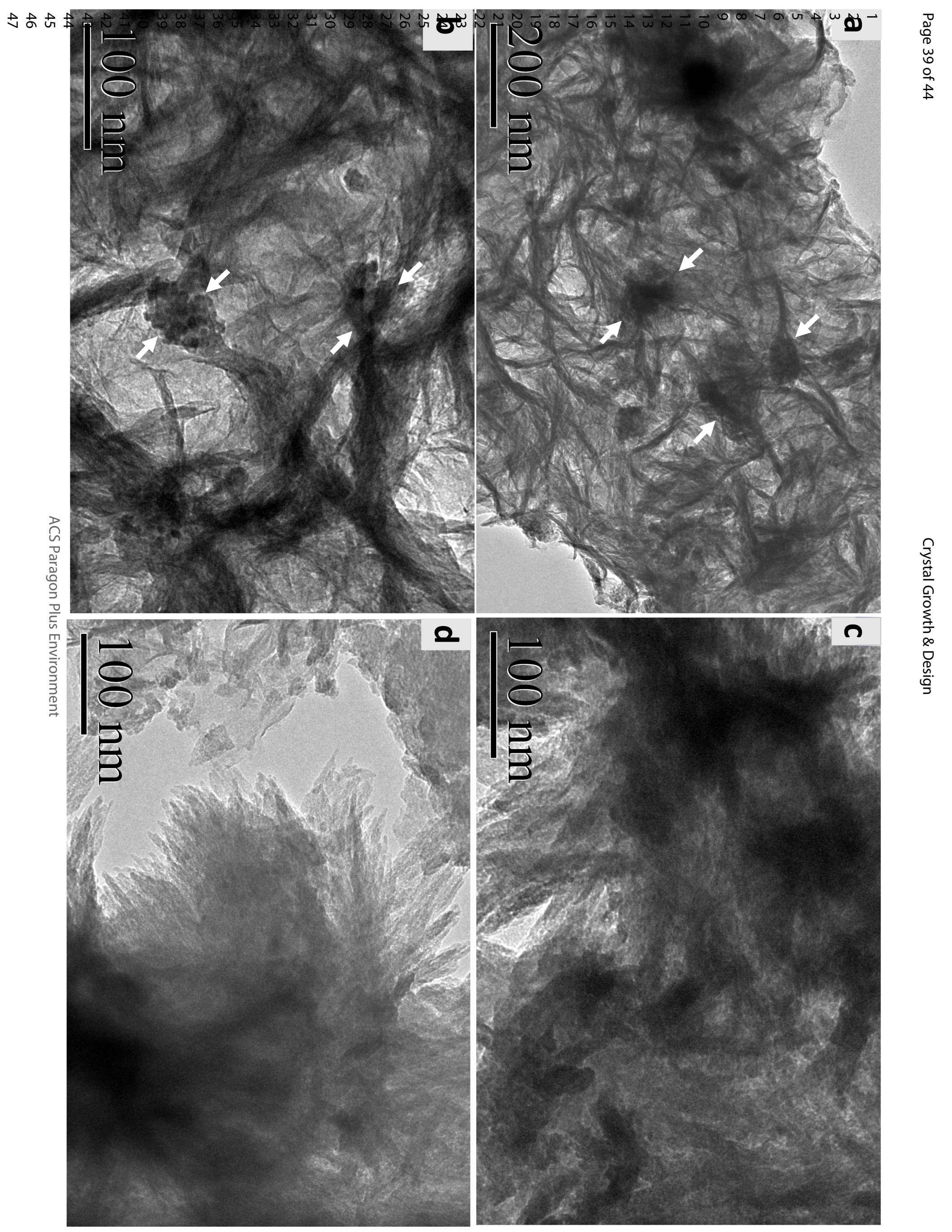




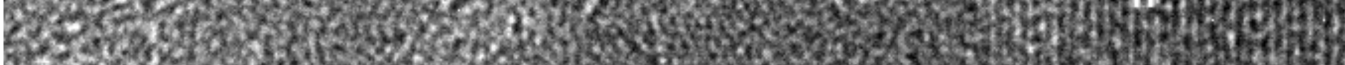

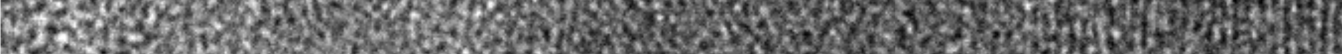

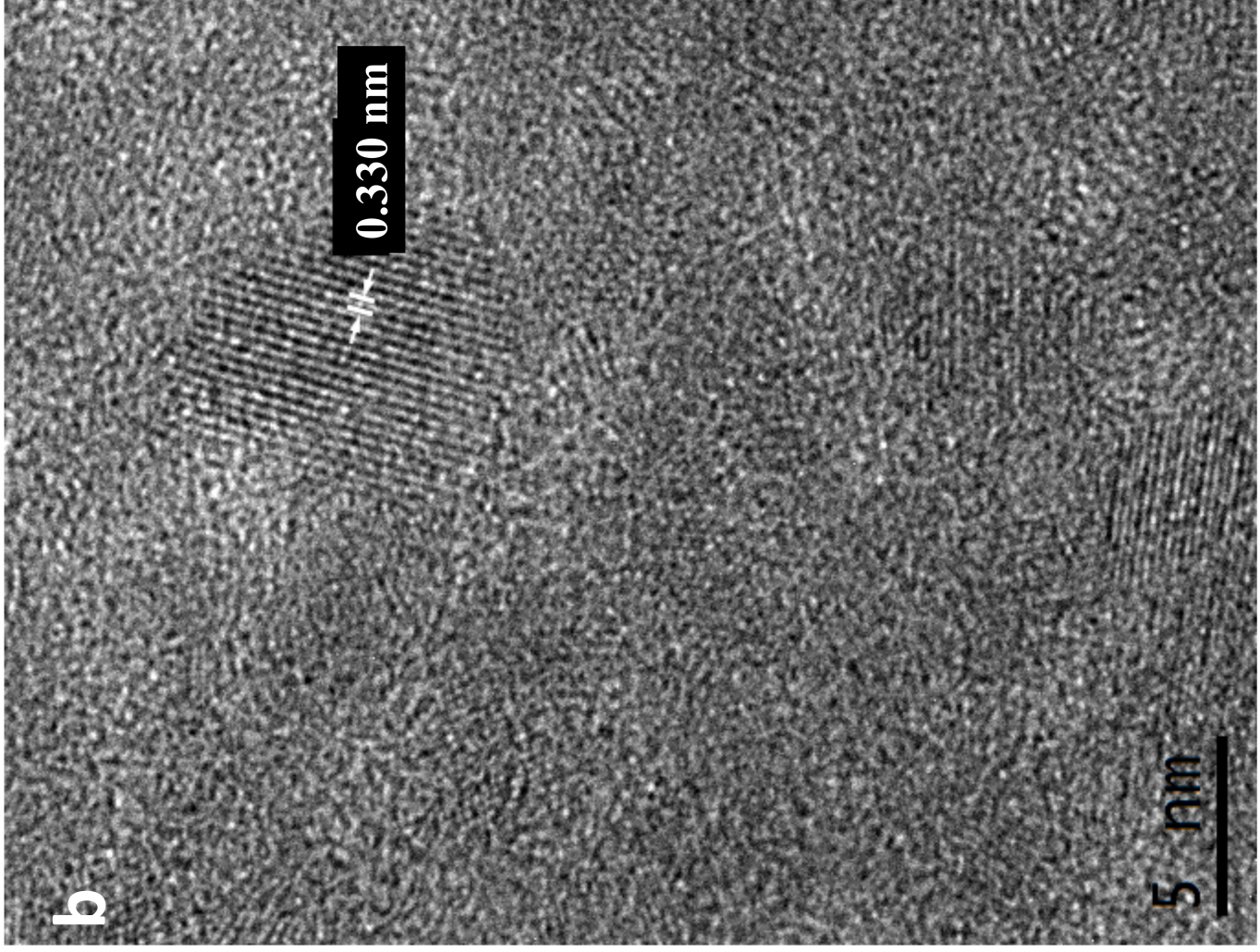
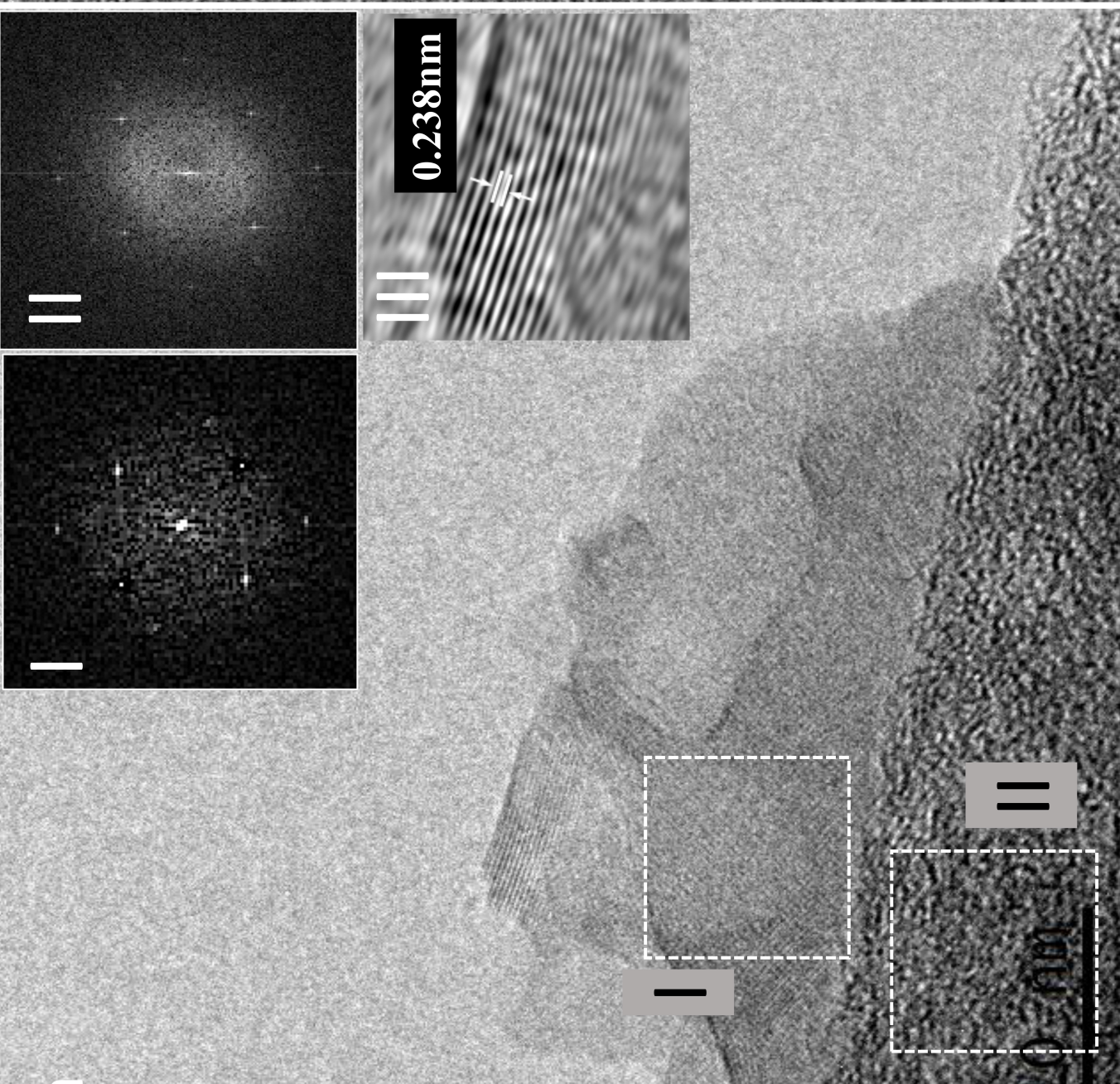

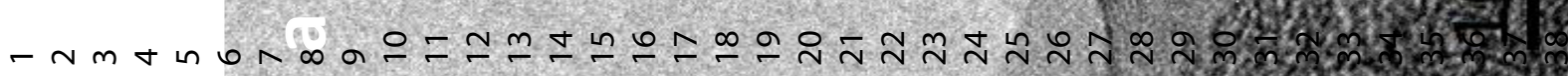




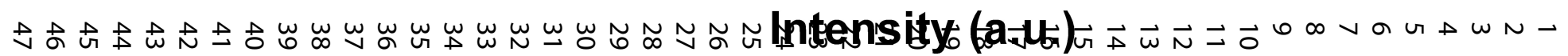
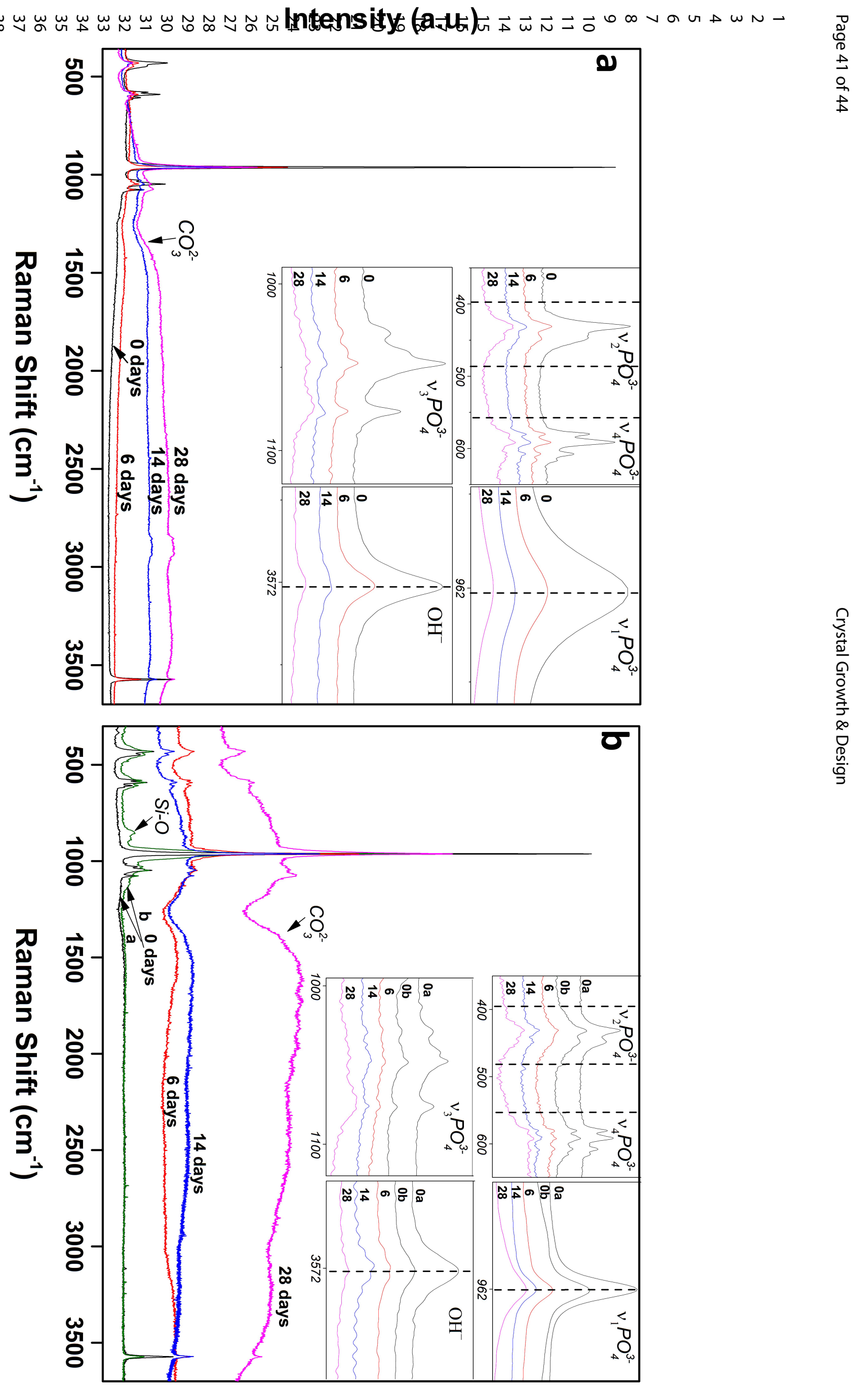


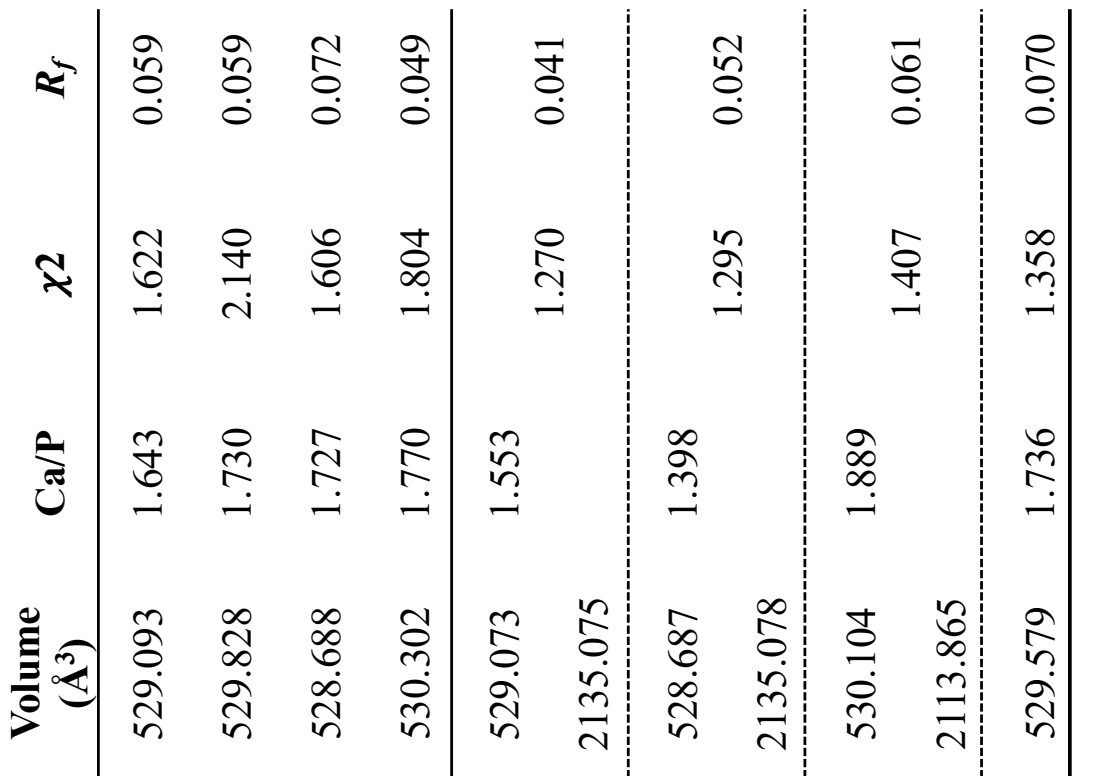

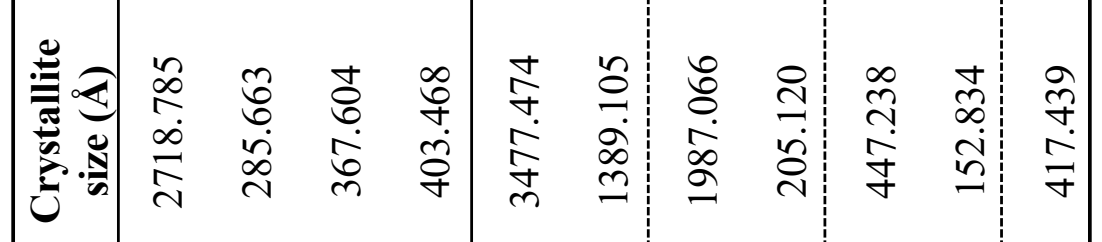

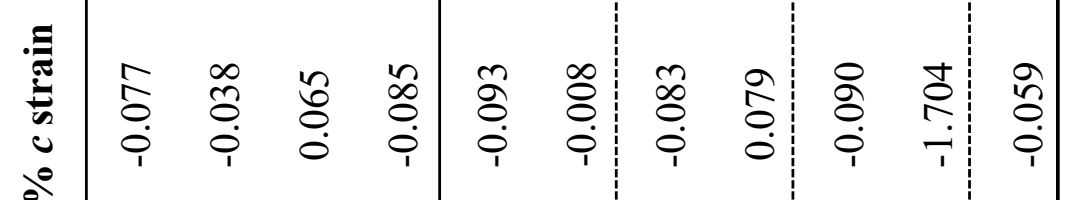

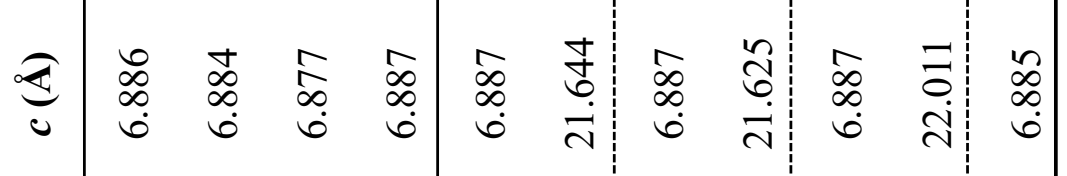

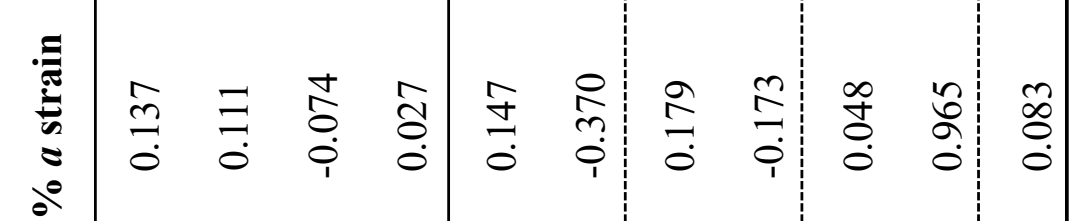

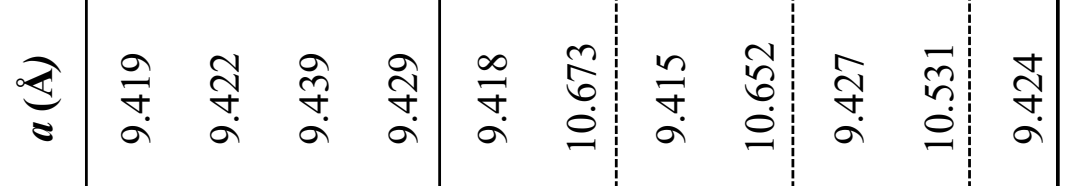

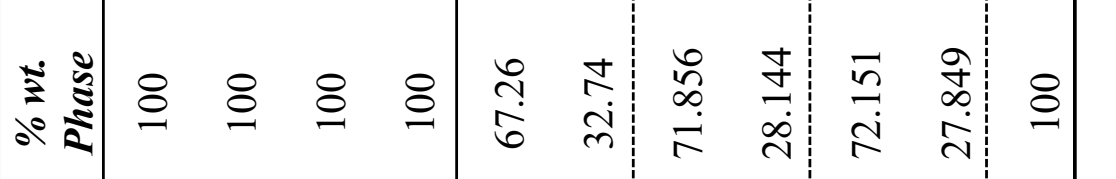

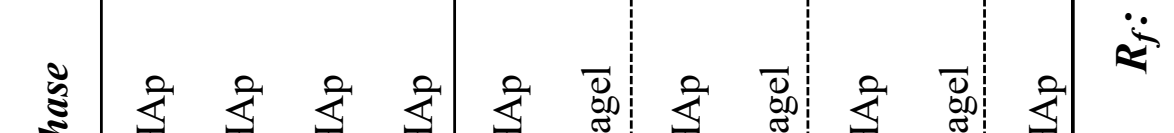




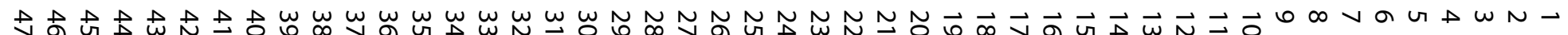

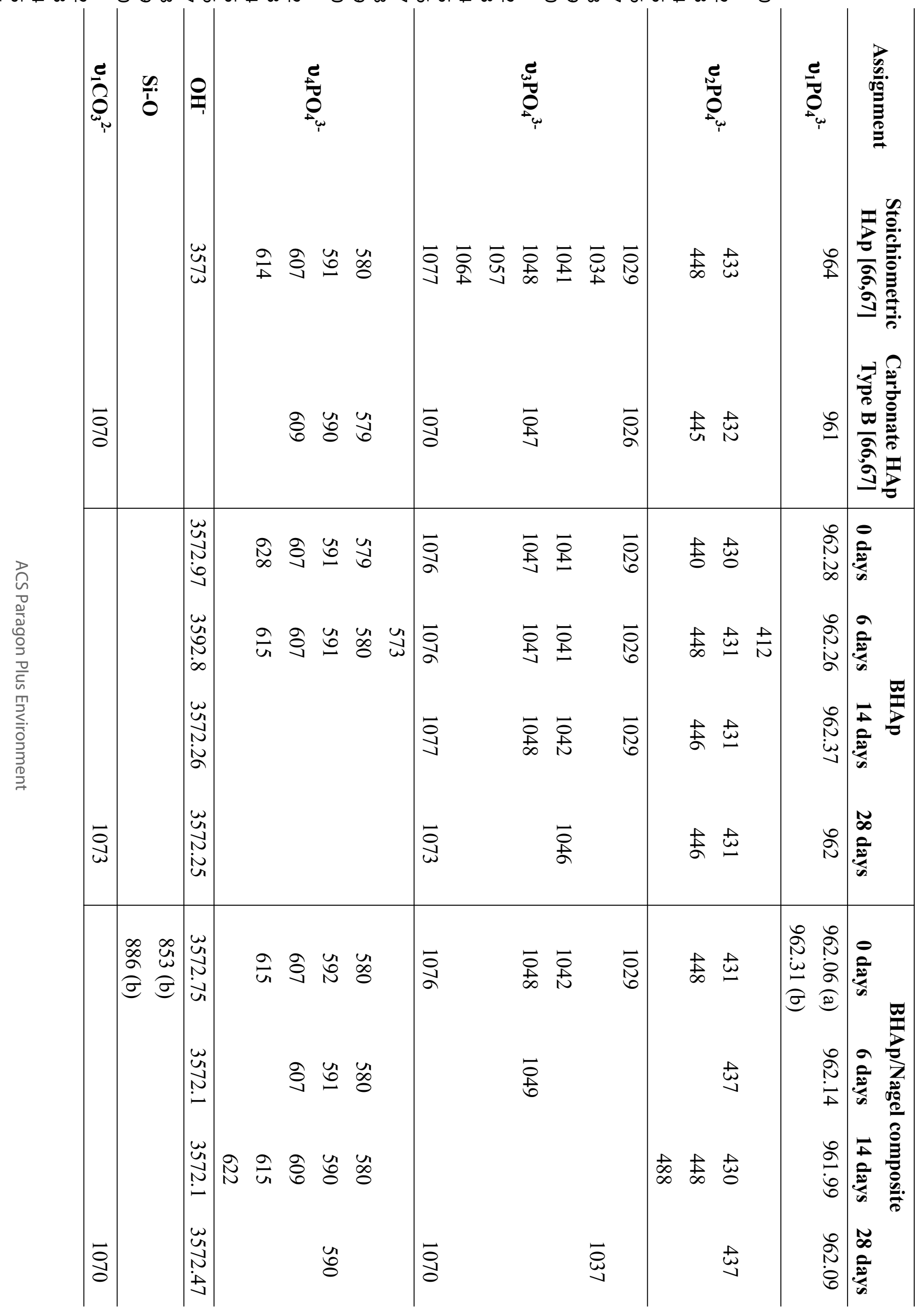




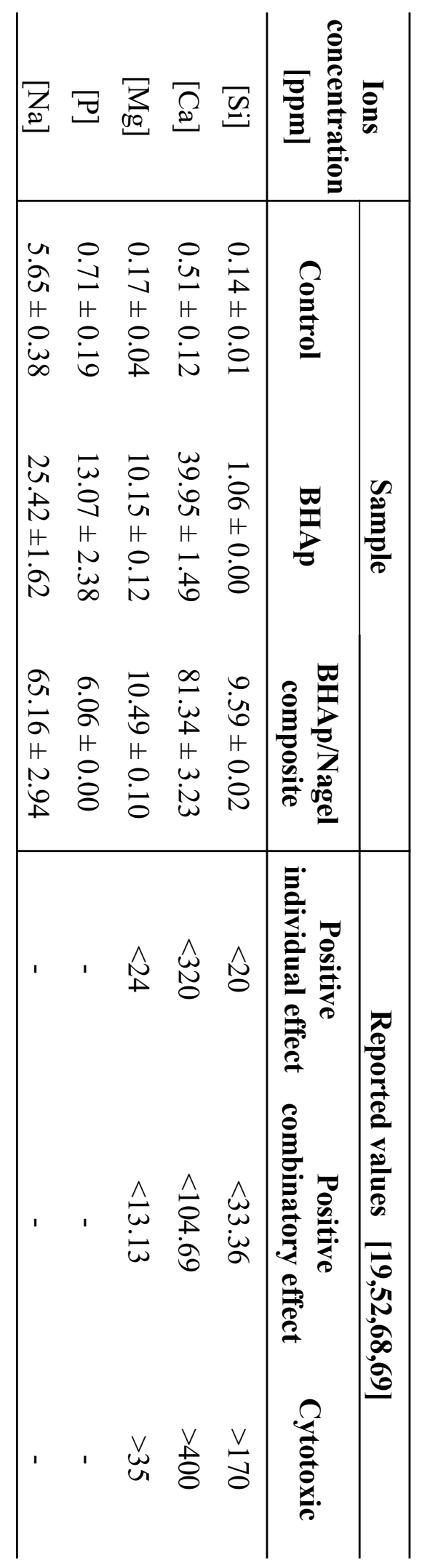

